\title{
ACERCA DEL VALOR MORAL DE LA SEGURIDAD JURÍDICA*
}

Ricardo García Manrique

Universidad de Barcelona

\section{La creencia en el valor moral de la seguridad jurídica}

\section{a) La creencia}

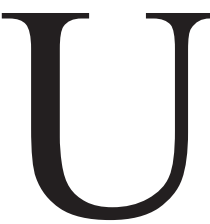

na creencia muy extendida socialmente, en especial entre los juristas, es la de que hay algo intrínsecamente bueno en el recurso a la técnica normativa en la que consiste el derecho. Esta bondad intrínseca puede explicarse más o menos en estos términos: cuando el poder político se ejerce mediante normas preestablecidas y conocidas por sus destinatarios, los individuos sujetos a dicho poder tienen la capacidad de predecir su ejercicio y, por lo tanto, de actuar en consecuencia; es decir, saben a qué atenerse con respecto a los agentes del poder político. Esta predicción es posible cuando las normas jurídicas son, en alguna medida, públicas, generales, claras, estables, de cumplimiento posible, irretroactivas y no contradictorias, y cuando los encargados de su aplicación (jueces y demás funcionarios) lo hacen de manera consistente y regular ${ }^{1}$. Por tanto, esta predicción es posible en alguna medida siempre que existe un sistema jurídico, puesto que un sistema jurídico siempre posee estas cualidades en alguna medida (en efecto, si no las poseyera en absoluto, su eficacia sería nula y, por lo tanto, no existiría o, en otros términos, no sería un sistema jurídico sino otra $\left.\operatorname{cosa}^{2}\right)$. Cuando

* El texto que sigue es el avance de un trabajo en curso.

${ }^{1}$ Se trata, claro está, de los ocho elementos de la moral interna del derecho (véase L. L. Fuller, The Morality of Law, New Haven y Londres, Yale University Press, $2^{a}$ ed., 1969, pág. 33 y sigs.).

${ }^{2}$ Ésta es la tesis de Fuller, que me parece correcta (véase L. L. Fuller, The Morality of Law, cit., pág. 39). No hace falta, por cierto, rechazar el positivismo para compartirla, como muestra R. Escudero Alday en la primera parte de su libro Positivismo y moral interna del derecho (Madrid, Centro de Estudios Políticos y Constitucionales, 2000); en contra de la posibilidad de hacer compatibles a Fuller y a Hart en este punto (que es lo que Escudero intenta, a mi juicio 
así sucede, se dice que los individuos sujetos al derecho tienen seguridad jurídica, esto es, se sienten seguros respecto del contenido de las normas y respecto del modo en que serán aplicadas; por tanto, a todos los que creen que este efecto de los sistemas jurídicos es intrínsecamente valioso en un sentido moral cabe considerarlos partidarios de la que podemos llamar "tesis del valor moral de la seguridad jurídica", que es el nombre que utilizaré para identificar esta creencia.

\section{b) Algunos ejemplos}

En el ámbito de la literatura jurídica, los autores que han defendido alguna versión de esta tesis son muchos; a modo de ejemplo, me referiré a tres de ellos: Gustav Radbruch, Elías Díaz y Felipe González Vicén.

En algunos trabajos breves que publicó inmediatamente después del final de la segunda guerra mundial, y que fueron muy difundidos, Gustav Radbruch replanteó la relación de tensión entre seguridad jurídica y justicia (ya establecida en trabajos anteriores ${ }^{3}$ ) como una manera de abordar algunos conflictos surgidos en el seno de ciertos procesos judiciales en los que se juzgaban hechos acaecidos durante los años del nazismo. Lo interesante de estos textos, en relación con nuestro asunto, es que en ellos Radbruch otorgaba prioridad a la justicia sobre la seguridad jurídica en ciertos casos, resolviendo a través de dicha prioridad alguno de esos procesos; sin embargo, al tiempo Radbruch reafirmaba con rotundidad el valor de la seguridad jurídica, no fuese que la prioridad otorgada, en ciertos casos, a la justicia lo oscureciese. Con esta intención, escribió: "Toda ley positiva lleva un valor en sí misma, independientemente de su contenido: es siempre mejor que la falta de ley, pues crea seguridad jurídica"; además, el ideal de la seguridad jurídica es considerado de igual valor que el de la justicia porque, en verdad, no es sino una forma de la misma justicia, dado que "la aplicación uniforme de un derecho injusto, su aplicación igual lo mismo hoy que mañana, su aplicación a unos y a otros, sin distinciones, corresponde precisamente a aquella igualdad que forma la esencia de la justicia"; por eso, "en la mayoría de los casos, la validez [entendida como obligatoriedad] del derecho positivo puede justificarse por las exigencias de la seguridad jurídica"; y, por tanto, "sólo en casos excepcionales, tratándose de leyes extraordinaria-

con éxito), véase J. Rodríguez-Toubes, "La relevancia conceptual y valorativa de la moral interna del derecho" (en Derechos y libertades, n 10, 2001, págs. 215-232), págs. 217-221; y la respuesta del propio Escudero, "La moral interna del derecho como objeto de debate" (también en Derechos y libertades, $\mathrm{n}^{\circ}$ 10, 2001, págs. 233-253).

${ }^{3}$ G. Radbruch, Filosofía del derecho (trad. J. Medina Echavarría, Madrid, Editorial Revista de Derecho Privado, 1933; es la traducción de la $3^{\text {a }}$ edición alemana de 1932; hay reedición en Granada, Comares, 1999), § 9, págs. 95-101. 
mente injustas, cabe la posibilidad de desconocer la validez de tales leyes, por razón de su injusticia"4. El ejemplo de Radbruch es significativo por ser el del "último gran teórico de la seguridad jurídica"s, y porque la rotunda afirmación del valor de la seguridad jurídica se produce precisamente en un contexto en el que lo que pretendía era otorgar prioridad (puntual) a la justicia sobre la seguridad, algo a destacar sobre todo cuando en los últimos tiempos se suele asociar a Radbruch con la afirmación de esta prioridad y no tanto con la defensa del valor de la seguridad jurídica ${ }^{6}$.

El segundo ejemplo es el de Elías Díaz, que defendió el valor de la seguridad jurídica en estos términos: "El Derecho proporciona al menos la seguridad mínima de poder saber con certeza lo que está prohibido y lo que está permitido. Y esto es siempre mejor, creo, que la total arbitrariedad o la absoluta inseguridad del no-Derecho. La mera existencia de un Derecho produce seguridad; puede decirse, desde esta perspectiva, que el valor seguridad (...) es algo que aparece irremediablemente cuando comienza a hablarse de lo que el Derecho es y de lo que el Derecho hace en la sociedad". Esta defensa venía seguida del establecimiento de un "segundo nivel" de la seguridad jurídica, en el cual aparecía vinculada con la justicia: "Tener seguridad jurídica no es sólo saber que existe un sistema legal vigente, por injusto que sea, no es sólo saber a qué atenerse, no es sólo saber lo que está prohibido y permitido por un ordenamiento jurídico. Tener seguridad jurídica es eso, que es sumamente importante, pero es también mucho más: es la exigencia de que la legalidad realice una cierta legitimidad, es decir, un sistema de valores considerados como imprescindibles en el nivel ético social alcanzado por el hombre y considerado por él como conquista histórica irreversible: la seguridad no sólo es un hecho, es también, sobre todo, un valor (...) No

${ }^{4}$ Estos pasajes se encuentran en G. Radbruch, "Arbitrariedad legal y derecho supralegal" (incluido en Id., Relativismo y derecho, trad. L. Villar Borda, Bogotá, Temis, 1992, págs. 2542), pág. 34; y en G. Radbruch, Introducción a la filosofía del derecho (trad. W. Roces, México D. F., Fondo de Cultura Económica, 1974), págs. 44, 51 y 52. Cabe insistir en el hecho, no siempre tenido en cuenta, de que el "giro iusnaturalista" de Radbruch no modifica esencialmente su modo de plantear la relación entre justicia y seguridad, que se mantuvo básicamente estable al menos desde la última edición de su Filosofía del Derecho, de 1932; en todo caso, como señala Alexy, los trabajos de posguerra suponen un "pequeño ajuste en su sistema"; véase R. Alexy, "A Defence of Radbruch's Formula" (en D. Dyzenhaus, ed., Recrafting the Rule of Law: The Limits of Legal Order, Oxford, Hart, 1999, págs. 15-39), págs. 17 y 32-33.

${ }^{5}$ F. González Vicén, "La obediencia al derecho" (incluido en Id., Estudios de filosofía del derecho, Universidad de La Laguna, 1979, págs. 365-398), pág. 381.

${ }^{6}$ Seguramente debido a la recuperación de la "fórmula de Radbruch" ["el derecho extremadamente injusto no es derecho"] por parte de Robert Alexy, aunque, desde luego, Alexy es plenamente consciente del valor que Radbruch otorgaba a la seguridad jurídica, también después de la experiencia del nazismo (R. Alexy, "A Defence of Radbruch's Formula", cit., págs. 32-33). 
habrá, en este sentido, seguridad si no existe, al propio tiempo, un suficiente respeto a las exigencias de la libertad y de la igualdad...". Por supuesto, este segundo nivel de la seguridad jurídica era claramente preferido al primero, pero lo que interesa destacar es que Elías Díaz dejaba claro que este primero también es valioso, dado que "la legalidad [equivalente al primer nivel de la seguridad] es siempre un progreso respecto de la arbitrariedad", y advertía de que "el orden, y la seguridad primaria que de él deriva, constituyen, en cualquier caso, una finalidad básica y fundamental para el Derecho. Es necesario no infravalorar alegremente este valor del orden..."7 . La concepción de la seguridad jurídica de Elías Díaz es significativa porque, aunque sostiene que en un "segundo nivel" la seguridad jurídica está vinculada con la justicia, también asume que la seguridad jurídica del primer nivel tiene "valor"; y porque, además, ha influido de manera notable en la filosofía del derecho española contemporánea ${ }^{8}$.

El tercer ejemplo es el de Felipe González Vicén. En un trabajo muy conocido y comentado, en el que rechazaba que pudiese existir una obligación moral de obediencia al derecho, explicaba que una de las fundamentaciones que se habían propuesto para tal obligación estaba constituida por la teoría de la seguridad jurídica. González Vicén descartaba que esta teoría, "ideología clásica de la clase burguesa acerca de la obediencia jurídica", justificase una obligación de obediencia al derecho, pero afirmaba taxativamente el valor que corresponde a la seguridad jurídica, pues escribía que "el problema que hay que plantearse no es el de si la seguridad jurídica constituye un valor, cosa evidente, sino el de si constituye un valor absoluto y supremo (...): ¿es verdaderamente y de por sí la seguridad jurídica un valor que fundamenta éticamente la obligatoriedad del Derecho?"; la respuesta de González Vicén no consistía en negar el valor de la seguridad jurídica, dado que "la seguridad jurídica es (...) un valor inmanente al Derecho, y lo es, porque establece la certeza en las relaciones sociales y verifica uno de los fines esenciales del Derecho, que es el aseguramiento de las relaciones humanas de convivencia"; sin embargo, continuaba, "esto no puede significar que esta verificación de uno de los fines del Derecho sea bastante para fundamentar éticamente la obediencia jurídica sin consideración a ningún

\footnotetext{
${ }^{7}$ Todos los pasajes pertenecen a E. Díaz, Sociología y filosofía del derecho (Madrid, Taurus, $2^{\text {a }}$ ed., 1980), págs. 41-42, 45-46, 42 y 47.

${ }^{8}$ Escudero señala las concepciones de la seguridad jurídica de Peces-Barba, Peces-Barba y Atienza como deudoras de la de Elías Díaz, en R. Escudero Alday, "Argumentos para la recuperación de la teoría de Lon L. Fuller” (en Anuario de Filosofía del Derecho, XIX, 2002, págs. 309-331), pág. 318.
} 
otro valor" " El ejemplo de González Vicén es significativo porque la valoración de la seguridad jurídica se produce en el contexto de la negación de la existencia de cualquier obligación moral de obedecer el derecho.

Es fácil observar lo que une a estas tres concepciones de la seguridad jurídica: las tres establecen un vínculo necesario entre la existencia del derecho y la generación de seguridad jurídica; las tres niegan que en la sola base de la seguridad jurídica pueda justificarse la obediencia al derecho (aunque la de Radbruch se acerca mucho a eso); pero las tres le atribuyen algún valor moral, vale decir, sostienen la tesis del valor moral de la seguridad jurídica.

\section{c) Relevancia de la creencia}

Creer que hay algo intrínsecamente bueno en el ejercicio del poder a través de normas previamente establecidas y conocidas por sus destinatarios tiene una consecuencia importante: dota de cierta legitimidad al poder jurídico y a su derecho, una legitimidad que es independiente del contenido y del origen de sus normas. Así, los que sostienen esta creencia han encontrado una respuesta a la vieja pregunta de San Agustín: "Quitada la justicia, ¿qué otra cosa son los reinos sino grandes latrocinios?"10. Su respuesta sería que entre los reinos (justos o no, democráticos o no) y los grandes latrocinios hay una diferencia importante, si los reinos se constituyen como estados de derecho, o incluso si simplemente recurren a la técnica normativa y respetan el principio de legalidad en su actuación. Esta diferencia importante consistiría en que bajo un régimen así sucede algo que es altamente improbable en los grandes latrocinios: los individuos saben a qué atenerse y pueden predecir la acción pública, y este hecho no es irrelevante desde un punto de vista moral.

Por tanto, la creencia en el valor moral de la seguridad jurídica constituye un dato importante a la hora de reflexionar sobre la legitimidad del derecho y del estado. Además, en tiempos de relativismo axiológico o de desconfianza ante el buen funcionamiento de los mecanismos de representación política, o cuando el derecho presenta un grado de complejidad tal que es difícil determinar su grado de justicia, esta legitimidad jurídica que podemos llamar "formal" gana fuerza correspondientemente, porque puede identificarse con mayor facilidad que la corrección material o genética de las

${ }^{9}$ F. González Vicén, "La obediencia al Derecho", cit., págs. 380, 382, 384 y 385 . Lo mismo se reitera en F. González Vicén, "La obediencia al derecho. Una anticrítica" (en Sistema, n 65, 1985, págs. 101-105), pág. 103.

${ }^{10}$ Agustín de Hipona, La ciudad de Dios (trad. L. Riber, Madrid, CSIC, 1992), IV-4, pág. 85. 
normas (cuando menos, no es difícil sentirlo así). La creencia en la legitimidad formal del derecho vendría a suponer lo siguiente: incluso si las normas jurídicas son injustas o no democráticas, o si no estamos seguros de que sean justas o democráticas, el derecho que genera seguridad en sus destinatarios es moralmente valioso en alguna medida; y de aquí no sería difícil deducir la existencia de una obligación prima facie de obediencia al derecho, o de una razón para la obediencia.

\section{d) La creencia contraria}

Frente a esta creencia tan arraigada, podemos colocar esta otra: resulta extraño que se valore moralmente la forma de hacer las cosas, en este caso la forma de ejercer el poder; parece que el poder debería ser evaluado sólo mediante los fines a los que sirve y no mediante los medios que utiliza para ello (siempre y cuando los propios medios no violen los fines). Los que así piensan, que no son pocos aunque es probable que sean menos que los anteriores, no suelen sostener la tesis del valor moral de la seguridad jurídica. Acusan a sus partidarios de "formalistas" y creen que el concepto de seguridad jurídica tiene un significado estrictamente instrumental o técnico. Creen que la seguridad que el derecho puede garantizar sólo es deseable si el derecho sirve a la justicia, pero que es indeseable cuando el derecho busca fines inicuos.

La intención de este trabajo es contribuir a determinar cuál de las dos creencias permite una mejor fundamentación racional. Para ello, examinaré algunos de los argumentos que se han propuesto en favor de la tesis del valor moral de la seguridad jurídica. Si tales argumentos se muestran insuficientes para justificarla, ganaría fuerza la creencia contraria aunque, claro está, eso no probaría que la tesis sea falsa: haría falta un argumento que justifique que la seguridad jurídica merece sólo una consideración instrumental o técnica, algo que sólo esbozaré al final.

\section{e) Definición de seguridad jurídica y otras concepciones de la misma}

Antes de seguir adelante, conviene precisar un poco más el concepto de seguridad jurídica. A partir de aquí, entenderemos por seguridad jurídica "la certeza respecto del contenido de las normas jurídicas vigentes y respecto del hecho de que las normas jurídicas vigentes son aplicadas de acuerdo con su contenido". Esta definición es de tipo lexicográfico, puesto que da cuenta de uno de los modos en que el término es usado habitualmente. Por ejemplo, coincide en esencia con las de Radbruch y Kelsen: para el primero, la seguridad jurídica no es "la seguridad por medio del derecho, la seguridad que el derecho nos confiere al garantizar nuestra vida o nuestros bienes contra el asesinato o el robo, etc., sino la seguridad 
del derecho mismo"11; para el segundo, la seguridad jurídica consiste "en que las decisiones de los tribunales son previsibles hasta cierto grado, y por ende, calculables, de suerte que los sujetos sometidos al derecho pueden orientarse en su comportamiento según las decisiones judiciales previsibles"12; y muchos otros autores han ofrecido definiciones similares ${ }^{13}$. Una definición como ésta supone una concepción que podemos llamar "formal" de la seguridad jurídica porque exige sólo lo que Pérez Luño ha llamado "suma de corrección estructural y funcional del derecho" ${ }^{14}$ o Liborio Hierro, "consistencia del sistema normativo"15; en cambio, no exige del derecho contenidos materiales concretos, salvo el de las normas secundarias, o normas que regulan la creación y aplicación de otras normas, de las que depende dicha corrección estructural y funcional.

Hay otras concepciones de la seguridad jurídica que pueden calificarse como "materiales" porque entienden que la seguridad jurídica no exige del derecho sólo corrección estructural y funcional sino también la justicia de sus normas o, al menos, de algunas de ellas; siendo así, no sería posible que un sistema jurídico injusto, o radicalmente injusto, generase "seguridad jurídica"16. Los que sostienen estas concepciones de la seguridad jurídica lo hacen probablemente con la intención de evitar la utilización del ideal del

${ }^{11} \mathrm{G}$. Radbruch, Introducción a la filosofia del derecho, cit., pág. 40.

${ }^{12}$ H. Kelsen, Teoría pura del derecho (trad. R. J. Vernengo, México D. F., UNAM, 1986), pág. 260.

${ }^{13}$ Por citar sólo monografías, véanse F. Lopez de Oñate, La certeza del derecho (trad. S. Sentís Melendo y M. Ayerra Redin, Buenos Aires, Ediciones jurídicas Europa-América, 1953), págs. 74-75; A. E. Pérez Luño, La seguridad jurídica (Barcelona, Ariel, 1991; hay 2a ed. de 1994 con leves modificaciones), pág. 22; N. Álvarez, Jalones para una teoría crítica de la seguridad jurídica (Madrid, 1995), pág. 9; J. L. Mezquita del Cacho, Seguridad jurídica y sistema cautelar (Barcelona, Bosch, 1989), vol. I, pág. 41; o F. Arcos, La seguridad jurídica: una teoría formal (Madrid, Dykinson, 2000), págs. 32-34.

${ }^{14}$ A. E. Pérez Luño, La seguridad jurídica, cit., págs. 23 y 26; esta doble exigencia estructural y funcional aparece reiteradamente en las definiciones de seguridad jurídica o en la enunciación de sus requisitos; véase, por ejemplo, T. Geiger, Estudios de sociología del derecho (trad. A. Camacho, G. Hirata, R. Orozco, México D. F., Fondo de Cultura Económica, 1983), pág. 92; H. Henkel, Introducción a la filosofía del derecho (trad. E. Gimbernat, Madrid, Taurus, 1968), pág. 92; o L. Recasens, Tratado general de filosofía del derecho (México, Porrúa, 1959), pág. 221.

${ }^{15}$ L. L. Hierro, "Seguridad jurídica y actuación administrativa" (en Id., Estado de derecho: problemas actuales, México D. F., Fontamara, 1998, págs. 59-77), pág. 60.

${ }^{16}$ Las concepciones materiales son, según Escudero, mayoritarias en España (R. Escudero, "La moral interna del derecho como objeto de debate", cit., pág. 249). La más claramente material es la de G. Peces-Barba, "La seguridad jurídica desde la filosofía del derecho" (en Id., Derecho y derechos fundamentales, Madrid, Centro de Estudios Constitucionales, 1993, págs. 261-279), págs. 278-279; en ocasiones se proponen "niveles" distintos de seguridad jurídica, como es el caso ya visto de Elías Díaz, el de M. Atienza, El sentido del derecho (Barcelona, Ariel, 2001), pág. 182 y, creo, el de A. E. Pérez Luño, La seguridad jurídica, cit., pág. 57. 
que venimos hablando en favor de regímenes políticos injustos o no democráticos, o con la intención de evitar el positivismo ideológico, siquiera moderado, en el que incurre todo aquel que sostiene la tesis del valor moral de la seguridad jurídica, tal como aquí se ha definido ${ }^{17}$. Tal propósito es encomiable; sin embargo, entiendo que la mejor forma de lograrlo no es la redefinición material de la seguridad jurídica, sino un atento examen de su valor en tanto concepto formal. En general, a estas concepciones materiales puede seguramente aplicarárseles lo que tanto Joseph Raz como Robert Summers han escrito respecto de las concepciones materiales del rule of law, también muy extendidas, a saber: que suponen una superposición de los ámbitos de denotación de distintos conceptos jurídicos, lo cual impide su precisa identificación, evaluación y, en caso de conflicto entre sí, ponderación ${ }^{18}$. En todo caso, estas concepciones materiales no se tendrán en cuenta aquí.

\section{f) Conceptos afines al de seguridad jurídica}

La creencia en el valor moral de la seguridad jurídica se muestra a menudo como creencia en el valor moral de otras cosas, y conviene recordar cuáles son. De hecho, el concepto de seguridad jurídica es propio de la teoría jurídica moderna, pero la creencia que nos ocupa, se dice, es tan antigua como la cultura occidental, aunque haya sido nombrada de otro modo. Suele citarse el último de los diálogos platónicos como uno de los primeros lugares donde se enuncia con claridad, como preferencia del gobierno de las leyes frente al gobierno de los hombres: "En la ciudad donde la ley sea señora de los gobernantes y los gobernantes siervos de esa ley, veo realizada su salvación y todos los bienes que otorgan los dioses a las ciudades"19. Esta misma preferencia ha sido expresada a través de la alabanza del imperio de

${ }^{17}$ Véase N. Bobbio, El positivismo jurídico (trad. R. de Asís y A. Greppi, Madrid, Debate, 1993), págs. 233-235.

${ }^{18}$ J. Raz, "The Rule of Law and its Virtue" (en Id., The Authority of Law, Oxford, Clarendon Press, 1979, págs. 210-229), pág. 211; R. S. Summers, “A Formal Theory of the Rule of Law" (en Ratio Juris, vol. 6/2, 1993, págs. 127-142), págs. 136-137 o "The Principles of the Rule of Law" (en Notre Dame Law Review, vol. 74, 1999, págs. 1691-1712), págs. 1709-1711. En España recogen estos argumentos F. Arcos, La seguridad juridica: una teoría formal, cit., págs 395-403 o L. Miraut, La teoría de la decisión jurídica de Benjamin Nathan Cardozo (Madrid, Dykinson, 1999), pág. 164.

${ }^{19}$ Platón, Las leyes, 715 (véase en la edición de J. M. Pabón y M. Fernández-Galiano, Madrid, Centro de Estudios Políticos y Constitucionales, $3^{a}$ ed., 1999, pág. 145). No obstante, la enunciación explícita de esta preferencia parece que hay que atribuírsela a Harrington, ya en el siglo XVII, quien en su Océana definía el buen gobierno como el "imperio de las leyes y no el de los hombres”, en J. Harrington, La república de Océana (trad. E. Díez-Canedo, México, Fondo de Cultura Económica, 1987), págs. 49-50. La indicación de que fue Harrington el primero en utilizar la conocida fórmula ("empire of laws and not of men") se encuentra en F. Laporta, "Imperio de la ley y seguridad jurídica" (en E. Díaz y J. L. Colomer, eds., Estado, 
la ley, del estado de derecho, del principio o principios de legalidad, de la igualdad ante la ley, de la justicia formal, de la moral interna del derecho o del rule of law. Todos estos conceptos han sido y son valorados moralmente por el mismo motivo: su puesta en práctica produce ese efecto referido al principio y atribuido a la seguridad jurídica, llámese predecibilidad, previsibilidad, orden, certeza o interdicción de la arbitrariedad. Sin duda, estos conceptos designan cosas distintas, por ejemplo: un tipo de estado (estado de derecho), un principio regulador de la acción pública (principio de legalidad), una cualidad de los actos de aplicación de las normas (justicia formal) o un conjunto de requisitos formales del derecho (moral interna del derecho o principios de legalidad); pero también es indudable que todas esas cosas están relacionadas entre sí, al menos de la manera indicada. Establecer con mayor precisión de qué modo se relacionan no sería muy difícil, pero sí prolijo, y por eso no lo haré aquí, a salvo de la indicación que contiene el párrafo siguiente. Lo que sí interesa es destacar que nos hallamos ante una única creencia: la creencia en que el efecto de previsibilidad generado por la seguridad jurídica o por cualquiera de los demás conceptos mencionados es un efecto moralmente valioso. Es posible, pues, que no nos hallemos tanto ante un complejo "universo ético", como señaló Francisco Laporta refiriéndose al conjunto de conceptos asociados con el del imperio de la ley, cuanto ante un complejo universo "lingüístico", dado que si los nombres y conceptos aquí implicados son muchos, el valor moral al que apuntan puede ser uno solo $^{20}$. Por lo tanto, puede aceptarse, en este sentido, la afinidad entre la seguridad jurídica y todos los demás conceptos señalados en este párrafo, con dos corolarios importantes: en primer lugar, los argumentos utilizados para justificar el valor moral de cualquiera de esos conceptos pueden ser tenidos en cuenta a la hora de analizar el posible valor moral de la seguridad jurídica; en segundo lugar, el resultado de este análisis debería valer no sólo en relación con la seguridad jurídica, sino también en relación con cualquiera de los demás conceptos.

Aunque he optado por no analizar aquí las relaciones existentes entre la seguridad jurídica y los conceptos afines a ella, sí es necesario advertir lo siguiente: varios de estos conceptos admiten una concepción formal y una concepción material o, si se quiere, una versión débil y una versión fuerte; esta dualidad afecta, en particular, al imperio de la ley, al estado de derecho

justicia, derechos, Madrid, Alianza, 2002, págs. 105-132), pág. 129. La conexión entre Platón y Harrington ha sido señalada también por M. Á. Ramiro, Utopía y derecho. El sistema jurídico de las sociedades ideales (Madrid, Marcial Pons, 2002), págs. 358-360.

${ }^{20}$ Véase F. Laporta, "Imperio de la ley. Reflexiones sobre un punto de partida de Elías Díaz” (en Doxa, n 15-16/I, 1994, págs. 133-145), pág. 134. 
y al rule of law. En su concepción formal, los tres exigen sólo cualidades formales del derecho; en su concepción material, los tres exigen además otras cosas: origen democrático de las leyes, en el caso del imperio de la ley, y reconocimiento de derechos fundamentales, en el caso del estado de derecho y del rule of $l a w^{21}$. Debe quedar claro que la afinidad de la seguridad jurídica con el imperio de la ley, el estado de derecho y el rule of law lo es con sus concepciones formales y no con sus concepciones materiales.

En lo que sigue, examinaré los tres argumentos que considero más relevantes en favor de la tesis del valor moral de la seguridad jurídica (o de cualquiera de los conceptos afines a ella): el de la autonomía, el de la justicia material y el de la justicia formal.

\section{El argumento de la autonomía}

El argumento de la autonomía en favor de la tesis del valor moral de la seguridad jurídica consiste básicamente en mostrar que existe un vínculo entre la seguridad jurídica y la autonomía individual ${ }^{22}$; según cuál sea ese vínculo, podemos distinguir dos versiones del argumento. En su primera versión, o versión fuerte, se afirma que la seguridad jurídica es condición suficiente del respeto y promoción social de la autonomía; en su segunda versión, o versión débil, se afirma que la seguridad jurídica es condición necesaria del respeto y promoción social de la autonomía. Antes de precisar los términos en los que se establece el vínculo entre seguridad jurídica y autonomía en cada una de las dos versiones y discutir su validez, conviene aclarar en qué sentido se utiliza el término "autonomía" y por qué nos hallamos ante un argumento especialmente relevante.

Podemos entender por "autonomía" la capacidad de un individuo para orientar significativamente su vida de acuerdo con sus propias decisiones. Esta escueta definición es suficiente para nuestros propósitos y, me parece, acorde con las que han sido propuestas, por ejemplo, por Nozick, Dworkin,

\footnotetext{
${ }^{21}$ Acerca de esta dualidad formal-material, véanse, por ejemplo: respecto del imperio de la ley, L. L. Hierro, "El imperio de la ley y la crisis de la ley" (en Id., Estado de Derecho: problemas actuales, cit., págs. 17-44); y M. Gascón, "El imperio de la ley: motivos para el desencanto" (en Jueces para la democracia, $\mathrm{n}^{\circ} 32,1998$, págs. 25-35); respecto del estado de derecho, E. Fernández, "Hacia un concepto restringido de Estado de Derecho" (en Sistema, no 138, 1997, págs. 101-114); R. de Asís, Una aproximación a los modelos de Estado de Derecho (Madrid, Dykinson y Universidad de Jaén, 1999), págs. 43-111; y F. J. Ansuátegui, "Las definiciones del Estado de Derecho y los derechos fundamentales" (en Sistema, n 158, 2000, págs. 91-114); respecto del rule of law, P. Craig, "Formal and Substantive Conceptions of the Rule of Law: An Analytical Framework" (en Public Law, otoño de 1997, págs. 467-487); B. J. Hibbits, “The Politics of Principle: Albert Venn Dicey and the Rule of Law” (en Anglo-American Review, vol. 23/I, 1994, págs. 1-31); y T. R. S. Allan, "Dworkin and Dicey: The Rule of Law as Integrity" (en Oxford Journal of Legal Studies, vol. 8/2, 1998, págs. 266-277).
} 
Nino o Laporta ${ }^{23}$. Sin duda, "el concepto de autonomía -ha escrito Silvina Álvarez- está lejos de contar con una definición o unos límites claros e incontestables. Tanto las características definitorias como las fronteras de la acción autónoma son objeto de constante análisis y revisión" ${ }^{24}$; sin embargo, hay dos cosas que quedan claras en su trabajo, y que aquí daremos por buenas: una, que la autonomía está casi unánimemente considerada como un ideal moral del más alto rango; y dos, que la formulación kantiana del ideal como una suma o combinación de racionalidad e independencia del sujeto sigue siendo válida. Por otra parte, la relevancia del argumento de la autonomía se funda en dos razones: la primera es que reviste especial solidez, dado que tanto el carácter moral del ideal de la autonomía cuanto una cierta conexión entre autonomía y seguridad jurídica, en los términos que veremos, son difíciles de cuestionar; la segunda, que seguramente deriva de la primera, es que se trata de un argumento muy extendido, aunque no siempre sea posible distinguir a cuál de sus dos versiones se recurre y aunque no siempre se recurra expresamente al ideal de la autonomía, sino a conceptos equivalentes en el contexto, tales como los de "dignidad" o "libertad"25; también, como veremos en la sección 4, el valor de la autonomía está en la base de la atribución de moralidad a la justicia formal.

\section{a) Primera versión: la seguridad jurídica como condición suficiente de la autonomía}

La primera versión del argumento de la autonomía puede enunciarse así: el derecho genera en los individuos sujetos al mismo la capacidad de predecir ciertas conductas ajenas, en particular las conductas de aquéllos que ejercen el poder público (y tanto más la genera cuanto más seguro sea). Esta capacidad de predicción favorece la autonomía del sujeto, que puede tomar decisiones en relación con su vida, planificándola en cierta medida.

${ }^{22}$ En adelante usaré "autonomía" como sinónimo de "autonomía individual".

${ }^{23}$ Véanse en R. Nozick, Anarchy, State and Utopia (Oxford, Blackwell, 1974), pág. 49; G. Dworkin, The Theory and Practice of Autonomy (Cambridge University Press, 1988), pág. 20; C. S. Nino, Ética y derechos humanos (Barcelona, Ariel, 1989), págs. 204-205; F. Laporta, "Imperio de la ley", cit., pág. 135.

${ }^{24}$ S. Álvarez, "La autonomía personal” (en E. Díaz y J. L. Colomer, eds., Estado, justicia, derechos, cit., págs. 153-175), págs. 153-154.

${ }^{25}$ A la hora de acreditar el valor del rule of law, Fuller, Raz y Summers lo conectan con el respeto de la dignidad individual, y Hayek y Rawls lo conectan con la libertad. Hayek sostiene la primera versión del argumento de la autonomía: véase en F. A. Hayek, Camino de servidumbre (trad. J. Vergara, Madrid, Alianza, 1976), pág. 114 y sigs.; como veremos, Raz (y probablemente Rawls) sostienen en cambio la segunda versión. No sabría decir cuál de las dos versiones sostienen Fuller o Summers, respectivamente en L. L. Fuller, The Morality of Law, cit., pág. 162, y R. S. Summers, “The Principles of the Rule of Law”, cit., pág. 1705. 
Por lo tanto, la seguridad jurídica generada por un sistema jurídico garantiza un cierto nivel de autonomía a todos los individuos sujetos a dicho sistema jurídico. Pues bien: si la seguridad jurídica respeta, promueve o garantiza una cierta autonomía, y si la autonomía es moralmente valiosa, habría una buena razón para afirmar que la seguridad jurídica es moralmente valiosa. Podemos decir que el argumento se basa en que la seguridad jurídica es condición suficiente del respeto y promoción social de un algún nivel de autonomía individual. Por ejemplo, y como mínimo, es condición suficiente de la capacidad para prever con antelación las consecuencias de ciertos actos (si la norma N establece: "Si A, entonces C", un individuo podrá elegir entre hacer o no hacer A, sabiendo de antemano que la consecuencia de ello será $\mathrm{C}$ o no $\mathrm{C}$ ): habiendo seguridad jurídica, uno "sabe a qué atenerse"26.

En esta versión, el argumento de la autonomía puede cuestionarse revisando las condiciones en las que se puede afirmar que estamos ante la posibilidad de actuar autónomamente y comparándolas con las condiciones generadas por la seguridad jurídica. Joseph Raz establece dos condiciones necesarias para que el ejercicio de las capacidades humanas de discernimiento y elección pueda ser considerado valioso: una es la independencia del sujeto, esto es, que el sujeto pueda tomar decisiones libremente, sin constricciones exteriores (un esclavo o un siervo no serían independientes); la segunda condición es la disposición de una adecuada gama de opciones, lo cual significa que las posibilidades de elección han de ser relevantes o significativas (uno de los dos ejemplos de "inadecuada gama de opciones" que propone Raz es el de un individuo que vive en el fondo de un pozo, es incapaz de salir de él, y puede elegir solamente las horas en que come y duerme, y si se rasca o no la oreja izquierda; el otro ejemplo es el de una mujer que vive en una pequeña isla desierta y dedica todo su tiempo y energías a escapar de una fiera que la persigue ${ }^{27}$. Si el ejercicio de las capacidades de discernimiento y elección tiene lugar en condiciones de dependencia, o si permite elegir sólo entre opciones no relevantes o planes de vida no valiosos, el ejercicio de dichas capacidades no puede ser considerado como un ejercicio de "autonomía"; de donde se deduce que no cualquier ejercicio de las capacidades humanas de discernimiento y elección es un ejercicio

${ }^{26}$ Recuérdese que éste es el argumento de E. Díaz, Sociología y filosofía del derecho, cit., págs. 41-42; lo ha sostenido también R. Escudero, Positivismo y moral interna del derecho, cit., págs. 527 o 539. Más adelante comprobaremos que un argumento similar sirve a Campbell para defender el valor moral de la justicia formal, en T. Campbell, La justicia. Los principales debates contemporáneos (trad. S. Álvarez, Barcelona, Gedisa, 2002), pág. 43.

${ }^{27}$ Véase J. Raz, The Morality of Freedom (Oxford, Clarendon Press, 1986), págs. 372378. 
de autonomía si, como hemos hecho, concebimos ésta como una capacidad cuya posesión es moralmente valiosa.

Y bien, ¿cuáles son las condiciones que genera la existencia de seguridad jurídica? Desde luego, no las que la autonomía exige, porque el hecho de que el poder político conforme su actuación con normas preestablecidas y conocidas por sus destinatarios no es garantía alguna ni de la independencia de los sujetos ni de la puesta a su disposición de una adecuada gama de opciones. Los ejemplos que ofrece la historia del derecho son numerosos y no es necesario referirse a ellos; en general, puede aceptarse que las condiciones de la autonomía exigen del derecho ciertos contenidos materiales y no meramente cualidades formales de carácter estructural y funcional. De aquí se sigue que la capacidad garantizada al sujeto por la seguridad jurídica, la capacidad de seguir o no seguir una norma, de saber a qué atenerse, la mera capacidad para elegir entre dos cursos de acción conociendo las consecuencias de cada uno de ellos, no aumenta la autonomía moralmente valiosa a disposición del sujeto, pues - de nuevo Raz- "la autonomía requiere que estén a disposición de una persona muchas opciones moralmente aceptables"28. Como es obvio, una norma jurídica no necesariamente pone a disposición del agente "muchas opciones moralmente aceptables": puede ser que no ponga a su disposición ninguna. Esta discordancia entre las condiciones de la autonomía valiosa y las condiciones garantizadas por la seguridad jurídica lleva a concluir que la seguridad jurídica no es condición suficiente de grado alguno de autonomía, y que el argumento de la autonomía, en su primera versión, no prueba la tesis del valor moral de la seguridad jurídica. Cabe añadir una reflexión acerca de los motivos que explican el recurso a este argumento: sus partidarios acaso manejan un concepto de autonomía distinto del asumido aquí, un concepto del que quedarían fuera las condiciones de independencia y adecuada gama de opciones, y que equivaldría a la mera capacidad de discernimiento y elección. Esta capacidad sí resulta aumentada por la seguridad jurídica, en tanto que la seguridad jurídica aumenta nuestro conocimiento. La cuestión, en fin, radica en lo que ha de entenderse por autonomía moralmente valiosa ${ }^{29}$.

${ }^{28}$ J. Raz, The Morality of Freedom, cit., pág. 378.

${ }^{29}$ Un argumento equivalente al del texto ha sido utilizado por Matthew Kramer para negar el valor moral de la moral interna del derecho; distingue Kramer entre autonomía como cualidad cognitiva ("capacidad de un sujeto para entender una norma y decidir seguirla o no seguirla") y autonomía como objetivo moral ("capacidad de un sujeto para orientar su propia vida") e imputa a Fuller la confusión entre ambas; véase en M. Kramer, In Defense of Legal Positivism. Law without Trimmings (Oxford University Press, 1999), págs. 58-62. 


\section{b) Segunda versión: la seguridad jurídica como condición necesaria de la autonomía.}

Todavía, empero, la relación entre autonomía y seguridad jurídica puede ponerse en otros términos con el fin de fundamentar en la primera el valor moral de la segunda. Puede sostenerse que, si bien la seguridad jurídica no es condición suficiente de la autonomía, sí es, al menos, condición necesaria de la misma; estaríamos así ante la que podemos denominar versión débil del argumento de la autonomía. Francisco Laporta es quizá quien mejor y de forma más explícita lo ha expuesto, aplicándolo a justificar la condición "esencialmente" moral del imperio de la ley, que "se extrae del principio ético de la autonomía individual", y escribiendo en otro lugar, con el mismo sentido, que "con el imperio de la ley es posible una sociedad injusta, pero sin imperio de la ley es imposible una sociedad justa. Para decirlo con algo más de precisión, el imperio de la ley es condición necesaria, pero no suficiente, de la sociedad justa" ${ }^{30}$. Argumentos similares han sido empleados por John Rawls, Joseph Raz y Jeremy Waldron para justificar el valor del rule of $l a w^{31}$. En todos estos casos, no se alega que la seguridad jurídica, el imperio de la ley o el rule of law garanticen de por sí grado alguno de autonomía; sólo se dice que la seguridad jurídica, el imperio de la ley o el rule of law son condición necesaria, aunque no suficiente, del respeto y promoción de

${ }^{30}$ Véase F. Laporta, "Imperio de la ley. Reflexiones sobre un punto de partida de Elías Díaz”, cit., págs. 135-139 y F. Laporta, “Imperio de la ley y seguridad jurídica”, cit., págs. 127128. El segundo trabajo refuerza la conexión, ya apuntada en el primero, entre imperio de la ley y seguridad jurídica; en cambio, las referencias a la autonomía, aunque presentes en ambos, se reducen en el segundo en beneficio de las referencias a la "justicia" o a la "sociedad justa". De todos modos, en ambos está clara la conexión entre las nociones de autonomía y justicia.

${ }^{31}$ J. Rawls, A Theory of Justice (Oxford University Press, 1973), § 38, págs. 235-243; J. Raz, "The Rule of Law and its Virtue" (en Id., The Authority of Law, Oxford, Clarendon Press, 1979, págs. 210-229), en especial págs. 221-222; y J. Waldron, “The Rule of Law in Contemporary Liberal Theory” (en Ratio Juris, vol. 2/1, 1989, págs. 79-96), págs. 85 y 94. Waldron señala expresamente que el rule of law es condición necesaria pero no suficiente del respeto de la autonomía. Raz escribe: "el derecho puede violar la dignidad de la gente de muchas formas. Respetar el rule of law no garantiza en absoluto que tales violaciones ocurran. Pero está claro que una deliberada falta de respeto por el rule of law viola la dignidad humana" (pág. 222). Raz vincula esta violación de la dignidad con la falta de respeto por la autonomía individual; sin embargo, no tengo claro si el valor que atribuye al rule of law es meramente instrumental o, por la razón derivada del pasaje transcrito, también moral. En cuanto a Rawls, escribe: "[El rule of law] proveerá una base más segura para la libertad y un medio más efectivo para organizar esquemas cooperativos; sin embargo, debido a que estos preceptos [los del rule of law] garantizan sólo la administración imparcial y regular de las normas, cualesquiera que éstas sean, ellos son compatibles con la injusticia. Imponen límites bastante débiles a la estructura básica, pero unos límites que no son en absoluto despreciables" (pág. 236); y más adelante (pág. 239) insiste en la conexión entre libertad individual y rule of law. No obstante, tampoco en este caso he podido esclarecer si todo ello supone una valoración moral del rule of law o solamente una valoración instrumental. 
la misma; y ésta sería una razón suficiente para justificar el valor moral de la seguridad jurídica o de conceptos afines.

Frente a esta versión del argumento de la autonomía, se puede razonar por dos vías: o bien admitiendo que la seguridad jurídica es condición necesaria del respeto y promoción social de la autonomía, pero rechazando que este hecho atribuya valor moral alguno a la seguridad jurídica; o bien rechazando que la seguridad jurídica sea condición necesaria del respeto y promoción de la autonomía individual. Prestaré mayor atención a la primera vía, más prometedora, y muy poca a la segunda, de tránsito difícil, además de innecesario si la primera nos lleva donde queremos ir.

Por la primera vía, me basaré en la siguiente idea: las condiciones necesarias para la realización de una acción no participan necesariamente de las cualidades de tal acción; en concreto, las condiciones necesarias para la realización de una acción moral no participan necesariamente de la cualidad moral de la acción, como se comprueba en el ejemplo siguiente: si estoy moralmente obligado a visitar a un familiar enfermo (acción moral), y si la única forma de llegar hasta él (condición necesaria) es tomando el tren, tengo el deber moral de tomar el tren; lo que se sigue de aquí es que "tomar el tren para visitar a un familiar enfermo" es una acción moral, pero no se sigue que "tomar el tren" sea una acción moral en cualquier caso. Obviamente, la acción “tomar el tren” no es, en sí (fuera de un contexto) ni moral ni inmoral; será una acción moral o inmoral en función del fin que la anime. Si se acepta esta idea, el argumento de la autonomía, en su segunda versión, no sirve para justificar el valor moral de la seguridad jurídica. En efecto, el argumento se basa en la idea opuesta de que una acción, por así decir, transmite su naturaleza a las condiciones necesarias de dicha acción, algo que veo difícil de admitir. Podemos admitir (aunque es discutible) que el respeto y la promoción social de la autonomía requiere recurrir, necesariamente, a un sistema jurídico que garantice la seguridad jurídica; pero de aquí no se sigue que la naturaleza moral de la acción "respetar y promover socialmente la autonomía individual" se comunique a todos los pasos necesarios para realizarla. En general, muchas acciones cuya naturaleza es estrictamente instrumental son necesarias para llevar a cabo fines morales, pero no por ello varía su naturaleza instrumental; sólo si la acción instrumental se realiza con un fin moral adquiere ella misma naturaleza moral. Acaso podría decirse que la segunda versión del argumento de la autonomía incluye una variante de la falacia de la división, consistente en atribuir a las partes las cualidades del todo.

Lo que se pretende mostrar quedará más claro añadiendo una consideración adicional: con independencia de que la seguridad jurídica sea o no condición necesaria del respeto y la promoción social de la autonomía, la 
seguridad jurídica puede ser también condición necesaria de ciertas violaciones de la misma. Ciertas, y particularmente graves, violaciones de la autonomía requieren, en un mundo complejo como el nuestro, el concurso de un sistema jurídico desarrollado, sin el cual no podrían ejecutarse. Matthew Kramer lo ha destacado en un análisis crítico de la supuesta moralidad de la moral interna del derecho ${ }^{32}$; años antes, Hart ya escribió lo siguiente: "el paso desde las formas simples de la sociedad (...) al mundo jurídico, con su legislatura centralmente organizada, sus tribunales, funcionarios y sanciones, trae consigo ventajas considerables, pero a un cierto precio (...). El precio es el riesgo de que el poder centralmente organizado pueda ser empleado para la opresión de muchos, cuyo apoyo no le resulta imprescindible, de una manera que el régimen más simple de reglas primarias no podía llevar a cabo"33. Si se acepta esto (y qué duda cabe de que la historia contemporánea ofrece múltiples ejemplos del recurso al derecho como medio necesario para perpetrar gravísimas ofensas a la autonomía individual), sólo queda aceptar que un sistema jurídico técnicamente avanzado genera un grado de seguridad jurídica mayor que un sistema jurídico primitivo, para concluir que la seguridad jurídica es condición necesaria de ciertas violaciones (gravísimas) de la autonomía individual, o condición necesaria de la represión de la autonomía individual de muchos (un modo aceptable de traducir la expresión "opresión de muchos", unos "muchos" que, advierte Hart, no encuentran en el sistema jurídico "nada que los llame a la lealtad, sino únicamente cosas a temer. Ellos son las víctimas del sistema, no sus beneficiarios"34). Ahora, si la seguridad jurídica es condición necesaria tanto del respeto y la promoción social de la autonomía como de su violación y represión, esto es, si la seguridad jurídica es condición necesaria para la realización de acciones tanto morales como inmorales, resulta impertinente atribuirle valor moral en todo caso, e igualmente impertinente decir que el poder político recurre a un medio intrínsecamente moral para llevar a cabo fines inmorales; y la impertinencia deriva, a mi juicio, de que no es razonable aceptar que las condiciones necesarias para llevar a cabo una acción moral posean ellas mismas, por esa razón, valor moral.

${ }^{32}$ M. Kramer, In Defense of Legal Positivism, cit., pág. 44: "Los regímenes perversos pueden encontrar en el derecho un vehículo indispensable para sus fines atroces. No es sólo que el funcionamiento del derecho no sirva para disuadir de la perversidad, sino que puede ser crucialmente útil para objetivos perversos. En breve, aunque la fe de Fuller en los efectos saludables de la promulgación de normas está, sin duda, justificada en ciertas circunstancias, puede resultar completamente infundada en otras".

${ }^{33}$ H. L. A. Hart, El concepto de derecho (trad. G. R. Carrió, Buenos Aires, Abeledo-Perrot, 1980), pág. 250.

${ }^{34}$ H. L. A. Hart, El concepto de derecho, cit., pág. 248. 
La anunciada segunda vía de razonamiento es la siguiente: podría ser que la seguridad jurídica no fuese siquiera condición necesaria del respeto y promoción social de la autonomía; esto podría afirmarse si se creyese posible ordenar las relaciones sociales al margen del derecho (por ejemplo, mediante mecanismos normativos institucionales no coactivos), pero de tal forma que la autonomía de todos quedase garantizada igual o mejor que a través del derecho. Se trata, sin duda, de una cuestión controvertida y de gran alcance, pero afortunadamente no es necesario desarrollarla aquí, puesto que la primera vía de análisis crítico de la segunda versión del argumento de la autonomía puede ser suficiente para rechazarla. En todo caso, a pesar de todos los intentos que tratan de demostrar la necesidad del derecho para una sociedad bien ordenada, es difícil encontrar pruebas fehacientes de que, en el futuro, no pueda existir una sociedad bien ordenada sin derecho; pero esta cuestión podemos dejarla al margen de nuestra línea argumental.

\section{c) Conclusión}

Si se acepta el razonamiento propuesto, las conexiones que pueden establecerse entre la autonomía y la seguridad jurídica o conceptos afines no bastan para otorgar a ninguno de éstos valor moral alguno: en primer lugar, porque la seguridad jurídica no es condición suficiente de la garantía de grado alguno de autonomía moralmente valiosa; en segundo lugar, porque el hecho de que la seguridad jurídica sea condición necesaria del respeto y promoción social de la autonomía moralmente valiosa no permite transmitir a la primera el valor moral de la segunda.

\section{El argumento de la justicia material}

\section{a) Enunciación. La tesis de la incompatibilidad o de la predisposición}

Un segundo argumento en favor de la tesis del valor moral de la seguridad jurídica podemos extraerlo a partir de un texto de Fuller ${ }^{35}$. En 1961, Hart había escrito que el respeto de los principios de legalidad es compatible con una "enorme iniquidad" y que, por tanto, de dicho respeto no podía deducirse una conexión muy relevante entre derecho y moral ${ }^{36}$. Fuller, con razón, se sintió aludido, pues él era el "crítico del positivismo" al que Hart hacía mención en ese lugar; era él quien había sostenido recientemente la tesis que Hart rechazaba (un rechazo, dicho sea de paso, en términos poco contundentes $)^{37}$. Como era de esperar, Fuller volvió a sostener en su libro de

\footnotetext{
${ }^{35}$ L. L. Fuller, The Morality of Law, cit., pág. 153 y sigs.

${ }^{36}$ H. L. A. Hart, El concepto de derecho, cit., págs. 255-256.

${ }^{37}$ L. L. Fuller, "Positivism and Fidelity to Law. A Reply to Professor Hart" (en Harvard Law Review, vol. 71/4, 1958, págs. 630-672; se trata de la réplica a H. L. A. Hart, "Positivism
} 
1964 que el respeto de los principios de legalidad, o de la moral interna del derecho, era incompatible con la persecución de ciertos fines radicalmente injustos, y ofreció una serie de argumentos en defensa de su tesis.

Merece la pena recordar lo que Fuller entendía por "moral interna del derecho": un conjunto de cualidades formales sin cuyo concurso es imposible crear y/o mantener un sistema jurídico: generalidad, publicidad, claridad, coherencia, estabilidad, irretroactividad y posibilidad de cumplimiento de las normas; y congruencia entre la acción oficial de aplicación de las normas y lo exigido por éstas. Si estas exigencias fuesen violadas en bloque, el resultado no sería, dice Fuller, un mal sistema jurídico, sino que no sería un sistema jurídico en absoluto $^{38}$. Es fácil comprobar que la moral interna del derecho es un concepto muy cercano al de la seguridad jurídica: el respeto de los elementos de la moral interna del derecho tiene como efecto la seguridad jurídica (los siete primeros garantizan lo que Pérez Luño llama corrección estructural del derecho; el octavo equivale a la corrección estructural del derecho; y recuérdese que la corrección estructural más la corrección funcional da lugar a un derecho generador de seguridad jurídica) ${ }^{39}$. Como correlato de esta cercanía conceptual, bien puede suponerse que todo argumento que acredite la moralidad de la moral interna del derecho puede servir también para acreditar la moralidad de la seguridad jurídica.

La incompatibilidad entre el respeto de la moral interna del derecho y la persecución de fines radicalmente injustos constituye, a juicio de Fuller, uno de los argumentos en favor de la moralidad de la moral interna del derecho. Tal incompatibilidad fue enunciada por Fuller en estos términos: es cierto

and the Separation of Law and Morals", publicado en ese mismo volumen), donde, por ejemplo, puede leerse (pág. 636): "El profesor Hart parece asumir que los fines perversos pueden tener tanta coherencia y lógica interna como los buenos fines. Yo, al menos, me niego a aceptar tal asunción (...) La coherencia y el bien tienen una mayor afinidad que la coherencia y el mal. Aceptando esta creencia, también creo que cuando los hombres son obligados a explicar y justificar sus decisiones, el efecto será generalmente la orientación de las mismas hacia el bien".

${ }^{38}$ Véase supra nota 2.

${ }^{39}$ A. E. Pérez Luño, La seguridad jurídica, cit., págs. 22-27. No está de más insistir en que el catálogo de la moral interna del derecho sirve también como catálogo de elementos del rule of law o del imperio de la ley; para comprobarlo, cotéjese L. L. Fuller, The Morality of Law, cit., pág. 33 y sigs., con J. Raz, "The Rule of Law and its Virtue”, cit., pág. 218; con R. S. Summers, "The Principles of the Rule of Law", cit., págs. 1693-1695; con J. Finnis, Natural Law and Natural Rights (Oxford, Clarendon Press, 1980), pág. 270; y, para el imperio de la ley, con F. Laporta, "Imperio de la ley y seguridad jurídica", cit., págs. 110-114. Conexiones expresas entre moral interna del derecho y certeza del derecho se encuentran en M. Atienza, El sentido del derecho, cit., pág. 182, y en R. Escudero, "Argumentos para la recuperación de la teoría de Lon L. Fuller”, cit., pág. 318. Rawls también asocia expresamente la moral interna del derecho con el rule of law, en J. Rawls, A Theory of Justice, cit., pág. 235. Una conexión entre moral interna del derecho y una concepción formal o restringida del estado de derecho se encuentra en R. de Asís, Una aproximación a los modelos de estado de derecho, cit., pág. 46. 
que "[la moral interna del derecho] es, respecto de un amplio espectro de cuestiones, indiferente hacia los fines sustantivos del derecho y puede servir a varios de tales fines con igual eficacia" (de hecho, los elementos de la moral interna del derecho son formales); pero, continuaba, "el reconocimiento de que la moral interna del derecho puede soportar y dar eficacia a una amplia variedad de fines sustantivos no debe llevarnos a creer que cualquier fin sustantivo puede ser adoptado sin compromiso de la legalidad"40. Esta tesis de la incompatibilidad entre respeto de la moral interna del derecho y violación de la moral externa del derecho (o justicia material) ha tenido bastante éxito, aunque también ha sido muy criticada ${ }^{41}$. Después de Fuller, la han defendido al menos John Finnis, Robert Summers o Trevor Allan ${ }^{42}$. Todos ellos han tratado de refinarla pero, en lo sustancial, su contenido ha seguido siendo el mismo: el respeto de ciertas formas jurídicas es incompatible con la comisión de ciertas injusticias sustantivas; y si ello fuese así, podría constituir la base para un buen argumento en favor del valor moral de la forma jurídica, de la moral interna del derecho o de la seguridad jurídica ${ }^{43}$. Más allá de eso, los autores que de un modo u otro han defendido la existencia de conexiones necesarias entre ciertas formas y ciertos contenidos jurídicos son muchos, pero no me ocuparé de ellos aquí ${ }^{44}$. Conviene,

${ }^{40}$ L. L. Fuller, The Morality of Law, cit., pág. 153.

${ }^{41}$ Véase la exposición y análisis del debate suscitado por la tesis de Fuller en R. Escudero, Positivismo y moral interna del derecho, cit., págs. 392-417, y en F. Arcos, La seguridad jurídica: una teoría formal, cit., págs. 139-150. Además, el primero se declara contrario a la tesis de Fuller, en tanto que el segundo, aun con matices, parece mostrarse partidario de su corrección.

42 J. Finnis, Natural Law and Natural Rights, cit., págs. 271-272; R. S. Summers,"A Formal Theory of the Rule of Law", cit., págs. 139-140, y "The Principles of the Rule of Law", cit., págs. 1707-1708; T. R. S. Allan, Constitutional Justice. A Liberal Theory of the Rule of Law (Oxford University Press, 2001), págs. 60-61.

${ }^{43}$ La modificación más significativa del argumento es la de restringir su validez a sistemas jurídicos liberal-democráticos (es el caso de Summers y Allan); pero entonces el argumento ya no tiene validez general y, por tanto, no tendré en cuenta esta variante. La modificación que introduce Finnis puede resumirse así: no se trata tanto de una incompatibilidad lógica entre principios de legalidad y fines injustos, sino de que los "tiranos" no tienen motivo alguno para respetar unos principios cuyo fin es garantizar ciertos valores (imparcialidad, reciprocidad, respeto por las personas) con los que no comulgan. A esto puede reponerse lo ya señalado en la sección anterior, a saber, que el fin de los principios de legalidad puede ser solamente garantizar la eficacia de un sistema jurídico complejo e injusto.

${ }^{44}$ Un ejemplo son los trabajos de Weinrib dedicados a justificar que la forma jurídica exige la inclusión en el derecho de ciertos contenidos sustantivos concretos; así E. J. Weinrib, The Idea of Private Law (Cambridge, Harvard University Press, 1995), "Legal Formalism" (en Yale Law Journal, vol. 97/6, 1988, págs. 949-1016), y “The Intelligibility of the Rule of Law” (en A. C. Hutchinson y P. Monahan, eds., The Rule of Law: Ideal or Ideology, Toronto, Carswell, 1987, págs. 59-84). Una crítica monográfica, y a mi juicio acertada, del formalismo defendido por Weinrib se encuentra en J. Raz, "Formalism and the Rule of Law" (en R. P. George, ed., Natural Law Theories, Oxford, Clarendon Press, 1992, págs. 309-340). 
por cierto, advertir de que lo que se diga a continuación en nada cuestiona, ni tiene directamente que ver con, la particular relevancia que cabe atribuir a la forma en el derecho, a todas luces indiscutible ${ }^{45}$.

Antes de examinar los argumentos ofrecidos por Fuller en favor de su tesis, cabe observar que la misma está formulada en términos muy imprecisos: la tesis establece que el respeto de la moral interna del derecho es incompatible con "una gran iniquidad" o con "una brutal indiferencia hacia la justicia y el bienestar humanos", pero compatible con muchos otros fines injustos. Fuller no precisa mucho más (ni tampoco lo hacen otros partidarios de la tesis), y eso dificulta el análisis, puesto que no es posible determinar qué concretos fines injustos son incompatibles con el respeto de la moral interna del derecho; por eso, podría hablarse de la existencia de una "predisposición hacia la justicia material" de aquéllos que respetan la moral interna del derecho, una predisposición siquiera sea por omisión, en el sentido de que si se respeta la moral interna del derecho es imposible llevar a cabo las violaciones de la justicia material más allá de un punto determinado, de manera que el legislador que no renuncie al respeto de la moral interna del derecho se ve obligado a renunciar a ciertas injusticias; precisamente porque no sabemos dónde situar este punto (ni, por tanto, el alcance de la incompatibilidad) es por lo que podría hablarse de una "tesis de la predisposición" (de los que respetan la moral interna del derecho hacia la justicia material) mejor que de una "tesis de la incompatibilidad" (entre moral interna del derecho e injusticia material) ${ }^{46}$. Quizá así se reflejaría mejor el sentido de lo que Fuller, Finnis, Summers o Allan quieren decir; en todo caso, el nombre es lo de menos ${ }^{47}$.

${ }^{45}$ Véase R. S. Summers, "How Law is Formal and Why it Matters" (en Cornell Law Review, vol. 82, 1997, págs. 1165-1229).

${ }^{46}$ Véase J. Rodríguez-Toubes, "La relevancia conceptual y valorativa de la moral interna del derecho", cit., págs. 226-227, donde afirma que entender la tesis de Fuller en términos de incompatibilidad entre moral interna y moral externa es un error.

${ }^{47}$ Un ejemplo de tesis cercana a la de Fuller pero más precisa es la que propone Ernesto Garzón Valdés en "Seguridad jurídica y equidad" (en Id., Derecho, ética y política, Madrid, Centro de Estudios Constitucionales, 1993, págs. 301-315): la tesis de la incompatibilidad entre seguridad jurídica y violación extrema de la equidad, entendiendo por equidad el respeto a la dignidad humana, y por violación extrema de la equidad una situación tal en la que el sistema político "tendría que aplicar un procedimiento formal y materialmente arbitrario para la imposición de sanciones, borrar toda diferencia entre los jurídicamente culpables e inocentes y hasta manifestar una cierta tendencia a castigar justamente a aquellas personas que, también de acuerdo con las disposiciones proclamadas, son inocentes (....) En esta situación -que Garzón ejemplifica con el terrorismo de estado argentino- "la violación extrema de la equidad vuelve imposible la seguridad" (págs. 312-313). Una incompatibilidad entre seguridad jurídica e injusticia establecida en estos términos puede aceptarse, pero creo que no es suficiente para aportar valor a la seguridad jurídica, pues ésta se declara expresamente compatible con otras gravísimas violaciones de la justicia. 
En definitiva, el argumento de la justicia material en favor de la tesis del valor moral de la seguridad jurídica podría establecerse en estos términos: el respeto de las exigencias de la seguridad jurídica (o de la moral interna del derecho) impide a un legislador y a su sistema jurídico la consecución de ciertos grados de injusticia material o, al menos, los predispone de algún modo hacia la justicia material. Si esto es así, parece haber una buena razón para creer que la seguridad jurídica está dotada de algún valor moral intrínseco y también para justificar la expresión "moral interna del derecho".

\section{b) Argumentos de Fuller en favor de su tesis y análisis de los mismos}

Fuller ofrece tres argumentos en defensa de su tesis de la predisposición o de la incompatibilidad. El primero es que la historia no ofrece ejemplos de compatibilidad entre respeto de la moral interna del derecho y groseras violaciones de la justicia material. El segundo es el argumento de la incompatibilidad entre precisión e injusticia: es muy difícil perseguir fines injustos por medio de normas precisas; por tanto, si las normas son precisas (tal como exigen la moral interna del derecho y la seguridad jurídica), tenderán a ser materialmente justas o no podrán llevar la injusticia más allá de un cierto grado. El tercero es el argumento de la publicidad: la necesidad de que las normas sean públicas (tal como exigen la moral interna del derecho y la seguridad jurídica) orienta al legislador hacia la justicia, dado que se ve obligado a hacer explícitos sus fines ante los destinatarios de las mismas, y ello, se supone, previene al legislador frente a ciertos fines injustos o, genéricamente, le previene frente a la injusticia. Los tres argumentos propuestos por Fuller pueden ser cuestionados como sigue.

El argumento histórico. En primer lugar, cabe dudar de que el argumento histórico sea, en verdad, un argumento, porque, incluso si fuese cierto el juicio de hecho que contiene (la ausencia de ejemplos de incompatibilidad entre respeto de la moral interna del derecho y groseras violaciones de la justicia material), no permitiría establecer un vínculo necesario entre moral interna del derecho y justicia, sino sólo un vínculo contingente, pues del hecho de que la historia no ofrezca tales ejemplos no se deduce que no pudiera haberlos habido ni que no pueda haberlos en el futuro. En segundo lugar, la historia sí ofrece esos ejemplos; como la tesis de la incompatiblidad (o de la predisposición) está formulada en términos imprecisos, es difícil saber en qué grado de injusticia está pensando Fuller cuando la considera incompatible con el respeto de la moral interna del derecho; pero, en todo caso, la esclavitud, la pena de muerte o ciertas guerras son ejemplos de graves violaciones de la justicia que han sido o son causadas a través de sistemas jurídicos que respetan la moral interna del derecho en alto grado y generan seguridad jurídica; además, no hay por qué pensar que en estos ca- 
sos el aumento del respeto por la moral interna del derecho o el aumento del grado de seguridad jurídica generada suponga necesariamente restricción alguna respecto de dichas injusticias sino, en cambio, mayor eficacia en la consecución de las mismas, tal como he apuntado a la hora de analizar el argumento de la autonomía.

El argumento de la imprecisión. Éste parece el argumento más débil de los tres y, a decir verdad, no se alcanza a comprender muy bien su sentido. Fuller lo defiende con un ejemplo que también puede utilizarse en contra suya; se trata de las dificultades que encontraron las autoridades sudafricanas de la etapa del appartheid para aplicar las normas racistas, pues en muchos casos resultaba muy difícil determinar cuál era la raza de una persona y, por tanto, aplicar la norma discriminatoria correspondiente. Esto bien puede ser cierto y, sin embargo, no constituir argumento alguno en favor de la tesis que se pretende probar, puesto que: (1) las normas que tienen en cuenta la raza de las personas pueden ser perfectamente justas, por ejemplo cuando se trata de normas de acción positiva o "discriminación inversa"; (2) hay normas injustas que recurren a criterios de distinción entre personas perfectamente precisos, o en todo caso mucho más precisos que el de la "raza", como es el criterio del "sexo" (así sucede con todas las normas en que se sostiene la discriminación sexual o de género); (3) además, el concepto de "raza" no es particularmente impreciso, si lo comparamos con muchos otros que usa habitualmente el derecho, y a cuyo recurso difícilmente puede renunciar (buena fe, diligencia, pena degradante, gravedad, etc.). En síntesis: no hay relación alguna entre el recurso a conceptos jurídicos indeterminados y la búsqueda de la injusticia, y viceversa, no hay relación alguna entre precisión y justicia material. Es más, suele decirse que la moralización contemporánea del derecho ha tenido lugar mediante la introducción de normas de principio en las constituciones, normas que son por definición menos precisas que las reglas.

Argumento de la publicidad. Tal como ha sido formulado (la publicidad de las normas orienta al legislador hacia la justicia material), este argumento supone dos cosas: una, que el legislador necesita del asenso o aquiescencia de los destinatarios de las normas jurídicas para poder llevar a cabo con éxito sus propósitos; y dos, que los destinatarios de las normas jurídicas asumen mayoritariamente una concepción correcta de lo justo. Si fuese así, es plausible pensar que el legislador se preocuparía de dictar normas justas, consciente de que, en caso, contrario sus normas tenderían a ser desobedecidas y, por lo tanto, sus fines se verían frustrados. Sin embargo, no es razonable creer que ambas suposiciones sean ciertas en todos los casos, aunque muy probablemente alguna de las dos, o las dos, sea cierta en algún caso. De hecho, el propio ejemplo ofrecido por Fuller en favor de su tesis 
es de dudosa utilidad ${ }^{48}$. Fuller explica que durante los años de gobierno del partido nacionalsocialista en Alemania los judíos que poseían un establecimiento abierto al público eran obligados a poner un cartel con la inscripción "comercio judío". Esta obligación no derivaba de norma jurídica alguna, sino de las órdenes de miembros del Partido, porque "los nazis -entiende Fuller-sabían que una provisión legal formal y pública suscitaría críticas en el extranjero"; en consonancia con ello, se ordenaba la retirada de tales carteles en la ciudad en que se fuese a celebrar una feria internacional, para que los extranjeros no los viesen; en Berlín, donde la presencia de extranjeros era constante, nunca llegó a haberlos y, en cambio, se obligaba a los judíos a pintar sus comercios con un color determinado al que los extranjeros, se supone, no podían dar un significado especial, pero sí los alemanes. No sé si esta historia es verídica, o exacta, pero en todo caso lo que presume Fuller es: o bien que el gobierno alemán no necesitaba del apoyo de sus ciudadanos para poner en práctica su política (pero sí del foráneo, al menos por omisión, puesto que trataba de evitar las críticas de los extranjeros), o bien que el gobierno alemán tenía este apoyo (pero no el foráneo). Tanto en un caso como en otro, el ejemplo demuestra precisamente que, respecto de sus ciudadanos (destinatarios habituales de la mayoría de las normas jurídicas), el gobierno alemán no tenía necesidad en este caso de ocultar su injusto propósito discriminatorio; y tampoco hubiera tenido necesidad de ocultarlo respecto de los extranjeros que visitaban Alemania si éstos hubieran tenido sentimientos antisemitas o si, por alguna razón, al gobierno alemán le hubiesen tenido sin cuidado sus críticas.

Hart, en un comentario crítico al libro de Fuller, explicó que un gobierno puede querer ocultar sus fines moralmente incorrectos bajo una legislación vaga, oscura e incluso secreta, pero que ello dependerá de la opinión que dichos fines merezcan a los destinatarios de la legislación o de su debilidad como gobierno, no de una conexión necesaria entre moral interna y externa del derecho ${ }^{49}$. En efecto, los ejemplos de normas injustas que gozan del favor de la mayoría de sus destinatarios o de normas injustas que se imponen en contra de la opinión de la mayoría de sus destinatarios son muchos, y desde luego parecen suficientes para descartar la idea de Fuller; podemos aceptar el juicio crítico de Hart y sostener que la necesidad de hacer públicas las normas jurídicas no garantiza en ningún sentido que sean justas.

\footnotetext{
${ }^{48}$ L. L. Fuller, The Morality of Law, cit., pág. 158.

${ }^{49}$ H. L. A. Hart, "Lon L. Fuller: The Morality of Law" (en Id., Essays in Jurisprudence and Philosophy, Oxford, Clarendon Press, 1983), pág. 353.
} 


\section{c) Conclusión}

Con base en los argumentos propuestos por Fuller, no es posible afirmar que el legislador que respeta la moral interna del derecho está predispuesto hacia la justicia material o se encuentra inhabilitado para cometer injusticias graves. En consecuencia, no encontraremos aquí un argumento en favor de la moralidad de la moral interna del derecho ni en favor de la tesis del valor moral de la seguridad jurídica. Una posible rehabilitación de la tesis de Fuller podría venir de la mano de la idea de la "pretensión de corrección", una pretensión que Alexy atribuye a todo sistema jurídico ${ }^{50}$. Desde luego, Alexy ha mostrado su simpatía hacia las ideas de Fuller ${ }^{51}$; y un buen conocedor y crítico de su pensamiento ha escrito recientemente que la pretensión de corrección puede ponerse en términos de "disposición [del derecho] a la corrección en la medida en que tiene rasgos que lo inclinan a la corrección", añadiendo a renglón seguido que "los análisis de Fuller en torno a la llamada «moral interna del derecho» no son sino una exposición de los elementos que disponen el sistema jurídico a la corrección (...) Estos rasgos no aseguran por sí solos corrección moral en el sistema jurídico. Tan sólo lo disponen a ella" 52 . En verdad es probable que la tesis fulleriana de la predisposición pueda reformularse en los siguientes términos: "el derecho tiene la propiedad disposicional de la corrección moral"; el análisis de esta versión de la tesis sería interesante, cuando menos para determinar si aporta algo distinto, aunque habrá que dejarlo para otra ocasión.

\section{El argumento de la justicia formal}

El tercer argumento del que me ocuparé es el de la justicia formal, que puede resumirse así: la justicia formal tiene valor moral en algún sentido; pero la generación de seguridad jurídica exige el respeto de la justicia formal; luego la generación de seguridad jurídica tiene en algún sentido valor moral. El argumento se basa, por tanto, en la valoración moral de la justicia

${ }^{50}$ R. Alexy, El concepto y la validez del derecho (trad. J. M. Seña, Barcelona, Gedisa, 1994), págs. 41-45. Similar intención tiene la idea de "pretensión de legitimidad" defendida por Ernesto Garzón, por ejemplo en E. Garzón Valdés, “Algo más acerca de la relación entre derecho y moral” (en Id., Derecho, ética y política, cit., págs. 317-335), o la idea de "pretensión de buena fe" o "pretensión oficial de justicia" de P. Soper, Una teoría del derecho (trad. R. Caracciolo, Madrid, Centro de Estudios Constitucionales, 1993), págs. 94-96. Acerca de todo ello y con intención crítica, véase J. Betegón, "Sobre la pretendida corrección de la pretensión de corrección” (en Doxa, nº 21-I, 1998, págs. 171-192).

${ }^{51}$ M. Atienza, "Entrevista a Robert Alexy" (en Doxa, n 24, 2001, págs. 671-687), págs. 673-674.

${ }^{52}$ A. García Figueroa, "El «derecho como argumentación» y el derecho para la argumentación. Consideraciones metateóricas en respuesta a Isabel Lifante" (en Doxa, n 24, 2001, págs. 629-653), pág. 650. 
formal y en la consideración de la justicia formal como condición necesaria de la seguridad jurídica; para analizarlo, procederé así: ofreceré primero un concepto de justicia formal; en segundo lugar, explicaré su conexión con la seguridad jurídica; en tercer lugar, daré cuenta de las razones en que se basa la valoración moral de la justicia formal; por último, cuestionaré estas razones como base para cuestionar el argumento.

\section{a) Concepto de justicia formal}

Para empezar, conviene definir lo que entendemos por justicia formal: "aplicación consistente y regular de las normas jurídicas vigentes". Una norma es aplicada consistentemente cuando es aplicada de acuerdo con su contenido, esto es, de acuerdo con lo que ella exige; una norma es aplicada regularmente cuando es aplicada de acuerdo con el modo en que ha sido aplicada en casos anteriores equivalentes; y esto con independencia de cuál sea el contenido concreto de la norma aplicada y, en particular, con independencia de su justicia material, de manera que en la apreciación de la existencia de justicia formal en la aplicación de una norma no juega ningún papel el contenido material de la misma ${ }^{53}$. Esta definición no es estipulativa, sino que pretende dar cuenta de un concepto presente en toda la historia de la reflexión sobre la justicia, desde Aristóteles, que la llamó "justicia legal"54, hasta Rawls, que prefiere la expresión "justicia como regularidad" 55 , pasando por Hart, que habla de "justicia en la aplicación del derecho"s6; en otras ocasiones la misma noción es aludida con los términos "legalidad" o

${ }^{53}$ En realidad, la justicia formal definida como un modo de aplicación de normas puede predicarse de la acción de aplicación de algunos tipos de normas no jurídicas (por ejemplo, las reglas de los juegos), pero esto ahora no importa.

${ }^{54}$ Aristóteles, Ética Nicomáquea, 1137b 10-25 (trad. J. Pallí, Madrid, Gredos, 1985, pág. 263); se trata del pasaje sobre el concepto de equidad. Sobre este uso aristotélico del término justicia véase F. Schauer, "Generality and Equality" (en Law and Philosophy, vol. 16/3, 1997, págs. 279-297), pág. 287; aunque habría que ponerlo en relación con la dicotomía poco antes establecida (1134 20-1135a 15) entre justicia natural y justicia legal.

${ }^{55}$ J. Rawls, A Theory of Justice, cit., pág. 58: "La aplicación regular e imparcial, y en este sentido justa [fair], del derecho podemos llamarla «justicia como regularidad». Esta es una expresión más sugestiva que «justicia formal»". Nótese que en la definición de justicia formal del texto he eliminado el elemento de la imparcialidad (que Rawls sí consigna) con el fin de no complicar en exceso el análisis, y con la esperanza de que tal restricción no lo pervierta; sobre este punto, véase D. Lyons, "On Formal Justice” (en Id., Moral Aspects of Legal Theory. Essays on Law and Political Responsibility, Cambridge University Press, 1993, págs. 13-40), págs. 32-37 (hay trad. de S. Álvarez, Aspectos morales de la teoría del derecho, Barcelona, Gedisa, 1998); y M. Kramer, "Justice as Constancy" (en Id., In Defense of Legal Positivism, cit.), pág. 33 .

${ }^{56} \mathrm{O}$ "justicia en la administración del derecho"; H. L. A. Hart, El concepto de derecho, cit., págs. 255 y 200. 
"igualdad ante la ley"57. También hay quien ha calificado como "formal" la idea de justicia simpliciter, pero esto podemos dejarlo ahora al margen ${ }^{58}$. Aquí supondremos que existen dos ideas diferentes, aunque puedan estar relacionadas: la de justicia material o sustantiva y la de justicia formal.

\section{b) Conexión entre la justicia formal y la seguridad jurídica}

La conexión entre la justicia formal y la seguridad jurídica no es difícil de establecer, tal como se han definido una y otra: la justicia formal (o aplicación consistente y regular de las normas jurídicas vigentes) es un elemento necesario de la generación de seguridad jurídica (o certeza respecto del contenido y del modo de aplicación de las normas jurídicas vigentes); en particular, el hecho de que los jueces u otros aplicadores del derecho conformen su acción a la justicia formal es una de las bases de la certeza respecto del modo de aplicación de las normas jurídicas, segundo y decisivo elemento de la seguridad jurídica. Por lo tanto, podemos decir que la acción formalmente justa de los aplicadores del derecho es condición necesaria de la generación de seguridad jurídica o, simplemente, que la justicia formal es condición necesaria de la seguridad jurídica. Lo mismo puede observarse también a través de la idea de la moral interna del derecho, cuyo octavo elemento, la congruencia entre la acción oficial de aplicación de las normas y lo exigido por éstas, puede considerarse sin más como equivalente a la justicia formal. Puede afirmarse, pues, que esta premisa del argumento es verdadera: la generación de seguridad jurídica exige el respeto de la justicia formal $^{59}$.

${ }^{57}$ Véase, por ejemplo, A. Ruiz Miguel, "Equality Before the Law and Precedent" (en Ratio Juris, vol. 10/4, 1997, págs. 372-391), pág. 372, donde escribe que la justicia formal establece que "los casos iguales deben ser tratados igual, lo que en la esfera de la aplicación de las normas jurídicas es especificado habitualmente a través del tradicional principio de la igualdad ante la ley". Por supuesto, la igualdad ante la ley que es equivalente a la justicia formal es la que ha sido denominada "igualdad en la aplicación de la ley", y no la "igualdad en el trato dado por la ley" o "igualdad en la ley", distinción que se encuentra por ejemplo en algunas sentencias del Tribunal Constitucional español (STC 49/1982, FJ $2^{\circ}$ y STC 144/1988, FJ 1º); un análisis de esta distinción se encuentra en A. Ruiz Miguel, "Las huellas de la igualdad en la Constitución" (en M. R. Mate, ed., Pensar la igualdad y la diferencia. Una reflexión filosófica, Madrid, Visor y Fundación Argentaria, 1995, págs. 109-129), págs. 111-116.

${ }^{58}$ Véase G. Radbruch, Introducción a la filosofía del derecho, cit., págs. 33-35.

${ }^{59}$ Acerca de las relaciones entre justicia formal, seguridad jurídica y moral interna del derecho: Pérez Luño define la corrección funcional del derecho (segunda exigencia de la seguridad jurídica) como "regularidad en la actuación de los órganos encargados de su aplicación", esto es, como justicia formal (A. E. Pérez Luño, La seguridad jurídica, cit., pág. 26); Peces-Barba equipara la justicia formal con la seguridad jurídica (G. Peces-Barba, "La seguridad jurídica 


\section{c) Las razones de la justicia formal}

Los que defienden el carácter moral de la justicia formal alegan para ello una de dos razones, o las dos. La primera es la siguiente: una acción justa es el resultado de aplicar una norma materialmente justa de un modo formalmente justo; por tanto, la justicia formal es una condición necesaria de la acción justa y, por eso, participa de alguna manera de la naturaleza moral de la justicia. Así puede interpretarse este famoso pasaje de Radbruch: "No solemos hablar de un juez «legalista», sino de un juez justo, puesto que todo juez atenido a la ley, es por eso, y sólo por eso, también al mismo tiempo un juez justo" ${ }^{60}$; lo cual concuerda con otro pasaje de una obra posterior en el que sostiene que la seguridad jurídica es una "forma de la justicia" y que ya he citado: "La aplicación uniforme de un derecho injusto, su aplicación igual lo mismo hoy que mañana, su aplicación a unos y a otros, sin distinciones, corresponde precisamente a aquella igualdad que forma la esencia de la justicia"61. Hart, por su parte, entiende que "aunque las normas más abominables pueden ser justamente aplicadas, en la mera noción de aplicar una norma de acuerdo con lo que ella exige tenemos el germen de la justicia"62. La segunda razón en favor de la moralidad de la justicia formal es ésta: hay algo intrínsecamente moral en la aplicación consistente y regular de las normas porque así se respetan las expectativas creadas por la existencia de las normas que después son aplicadas; al respetar estas expectativas, se aumenta la capacidad de previsión de los individuos, y así se favorece su autonomía.

Obsérvese que la primera razón se basa en la asociación de la justicia formal con la justicia material, derivando el valor moral de la primera desde el de la segunda; es decir, la justicia formal tendría valor moral por participación del valor moral de la justicia material, o bien, la justicia formal tendría valor moral por ser condición necesaria de la justicia material. En cuanto a la segunda razón, no se basa en ese vínculo, sino en el respeto o aumento de la autonomía individual por parte de la acción formalmente

desde la filosofía del derecho", cit., pág. 279); y Rawls, en algún pasaje, identifica prácticamente la justicia formal con la moral interna del derecho (J. Rawls, A Theory of Justice, cit., págs. 59-60).

${ }^{60}$ G. Radbruch, Filosofía del derecho, cit., págs. 112-113.

${ }^{61}$ G. Radbruch, Introducción a la filosofía del derecho, cit., pág. 44.

${ }^{62}$ H. L. A. Hart, El concepto de derecho, cit., pág. 255. En este modo de valorar la justicia formal le siguen D. N. MacCormick, "Natural Law and the Separation of Law and Morals" (en R. P. George, ed., Natural Law Theories, cit., págs. 105-133), págs. 121-125; y, con alguna vacilación, K. Greenawalt, "Too Thin and Too Rich: Distinguishing Features of Legal Positivism" (en R. P. George, ed., The Autonomy of Law, Oxford University Press, 1996, págs. 1-29), págs. $12-13$ y 28 . 
justa, mediante la aplicación de cualesquiera normas; en este caso, la justicia formal tendría un valor derivado del que le corresponde a la autonomía. Ambas razones atribuyen valor moral a la acción formalmente justa con independencia de cuál sea la norma aplicada a través de dicha acción, pero extraen la moralidad de la justicia formal de fuentes diferentes. Dicho lo cual, sin embargo, creo posible que esta dualidad sea sólo una apariencia y que, en realidad, ambas fuentes de moralidad sean una sola; pero no abordaré esta cuestión o, al menos, no directamente.

\section{d) Análisis de las razones}

El argumento de la justicia formal en favor de la tesis del valor moral de la seguridad jurídica parece ser lógicamente correcto; si la justicia formal fuese condición necesaria de la seguridad jurídica, y si la justicia formal tuviese valor moral, podría afirmarse que la seguridad jurídica adquiere valor moral. Además, ya hemos visto que la primera premisa puede darse por buena; en cambio, la verdad de la segunda premisa puede cuestionarse; y si puede mostrarse que es una premisa inaceptable, estaremos en condiciones de descartar el argumento.

Abro aquí un pequeño paréntesis para aclarar que el ya examinado argumento de la autonomía (en su segunda versión) y el de la justicia formal son netamente distintos, aunque en ambos se trate de dotar de valor moral a la seguridad jurídica a partir de su relación necesaria con otros conceptos supuestamente dotados de valor moral: obsérvese que, en el primer caso, se sostiene que la seguridad jurídica es condición necesaria de la autonomía, y del valor moral de la segunda se deriva el de la primera; en el segundo caso, se sostiene que la justicia formal es condición necesaria de la seguridad jurídica, y del valor moral de la primera se pretende derivar el de la segunda. A mi juicio, la primera inferencia es incorrecta y la segunda es correcta (me refiero a la inferencia en sí, con independencia de que la autonomía y la justicia formal tengan o no valor moral). La diferencia estriba, claro está, en que en el primer caso la seguridad jurídica ocupa el lugar de condición necesaria (de la autonomía) y en el segundo caso ocupa el lugar de condición suficiente (de la justicia formal). Aunque no estoy versado en lógica general ni deóntica, entiendo que nuestra forma habitual de razonar es coherente con este argumento: si una acción A es condición necesaria de otra acción $\mathrm{B}$, y si A es una acción moral, $\mathrm{B}$ también lo será de algún modo, puesto que al hacer B estamos haciendo, o hemos hecho, también A; es decir, nuestro comportamiento incluye un elemento moral, porque no puede darse B $\sin \mathrm{A}$ (por ejemplo, no puede darse la seguridad jurídica sin justicia formal). En cambio, si una acción A es condición necesaria de otra acción $\mathrm{B}$, y si $\mathrm{B}$ es una acción moral, de aquí no se sigue que A lo sea en ningún sentido; la ac- 
ción A no incluye necesariamente un elemento moral, porque puede que se dé A pero no B y, por tanto, no aparezca el elemento de moralidad por ninguna parte. Esto puede asociarse, siquiera intuitivamente, con la falacia del consecuente pero, sobre todo, como ya dije, con la falacia de la división.

El análisis crítico de la premisa "la justicia formal tiene valor moral" ha de consistir en la ponderación de las dos razones ofrecidas en favor de la moralidad de la justicia formal. La primera razón era: "la justicia formal es condición necesaria de la justicia material" o "la justicia formal participa de la naturaleza de la justicia material". Respecto de esta razón, Kelsen señaló en su día que no hay conexión alguna entre la justicia de las normas y la forma en que éstas se aplican: "No hay que confundir el principio de igualdad, postulado por la autoridad que crea la ley con la intención de hacerla igualitaria, con el principio de igualdad ante la ley, destinado a las autoridades que aplican la ley a casos concretos. Los órganos que aplican la ley, al decidir un caso, no establecen ninguna diferencia que no se encuentre en la ley que se va a aplicar, es decir, aplican la ley tal como se debe hacer según su significado. Éste es el principio de legalidad, de la legitimidad inmanente a cualquier orden legal. A veces se presenta este principio como justicia de la ley, pero en realidad no tiene nada que ver con la justicia"63. Más adelante, han insistido en lo mismo otros autores que se han ocupado de la justicia formal, como es el caso de David Lyons o Frederick Schauer. Lyons, que se dirige contra la afirmación antes citada de Hart (relativa al "germen de la justicia"), insiste, entre otras cosas, en el hecho de que la justicia no siempre es efecto de la aplicación consistente de una norma ${ }^{64}$. Por su parte, Schauer

${ }^{63}$ H. Kelsen, ¿Qué es justicia? (trad. A. Calsamiglia, Barcelona, Ariel, 1991), pág. 51 (la cursiva es mía). Otros autores que le siguen en este punto son F. Laporta, "El principio de igualdad: introducción a su análisis" (en Sistema, n 52, 1985, págs. 23-43), págs. 6-7; W. Sadurski, "Equality Before the Law: A Conceptual Analysis" (en Australian Law Journal, vol. 60, 1986, págs. 131-138), pág. 132; G. Peces-Barba et al., Curso de Derechos Fundamentales (Madrid, BOE y Universidad Carlos III, 1995), págs. 284-285; y L. L. Hierro, "Las huellas de la desigualdad en la Constitución" (en Id., Estado de Derecho: problemas actuales, cit., págs. 103-127), pág. 104. Examinaré después la opinión contraria de Alfonso Ruiz Miguel.

${ }^{64}$ D. Lyons, "On Formal Justice”, cit., pág. 28. Este trabajo hizo recapacitar a Hart en los siguientes términos: "Veo ahora, en gran parte como resultado del ensayo del profesor Lyons sobre la justicia formal, que un argumento similar al mío contra Fuller puede ser utilizado para mostrar que mi afirmación hecha en el Ensayo 2 ["Positivism and the Separation of Law and Morals"] y repetida en mi Concept of Law de que una mínima forma de justicia es inherente a la misma noción de aplicar una norma de acuerdo con su sentido propio a todos los casos pertinentes está parecidamente equivocada. No estoy seguro de que sea así, pero sí de que mi afirmación requiere una revisión considerable" (H. L. A. Hart, Essays in Jurisprudence and Philosophy, cit., pág. 18). Véase también M. Kramer, "Justice as Constancy”, cit., pág. 28, ponderando las razones de uno y de otro. La cercanía entre Hart y Fuller en este punto ha sido señalada por el propio D. Lyons, Ética y derecho (trad. M. Serra Ramoneda, Barcelona, Ariel, 1986), pág. 86, por M. Martin, The Legal Philosophy of H. L. A. Hart. A Critical Appraisal 
apunta que no hay ninguna relación necesaria entre los conceptos de justicia y norma ni, por tanto, entre los de justicia y aplicación de normas ${ }^{65}$. Teniendo en cuenta sus argumentos, podemos cuestionar la primera razón en favor de la moralidad de la justicia formal como sigue.

Ante todo, debe advertirse que la aplicación consistente y regular de las normas no siempre produce un resultado justo. No lo hace si la norma aplicada no es (materialmente) justa, pues la aplicación consistente y regular de una norma injusta da lugar a un trato desigual para iguales o a un trato igual para desiguales, y ambas cosas son injustas; de este modo, la consecución de lo justo puede requerir precisamente lo contrario: la desviación respecto de la norma existente a la hora de su aplicación. Obsérvese que lo justo no consiste en tratar igual o desigualmente a los considerados iguales o desiguales por una norma, sino a los que efectivamente son iguales o desiguales desde el punto de vista de la justicia, al margen de que la norma lo reconozca así o no. En otras palabras, las categorías de personas o de actos establecidas por una norma son a priori irrelevantes a la hora de determinar si un acto (aunque sea de aplicación de una norma) es materialmente justo o no. Por otra parte, incluso si admitiésemos que el resultado justo exige la aplicación consistente y regular de una norma, de nuevo podemos recurrir a un tópico antes utilizado a la hora de abordar el análisis del argumento de la autonomía, el de la falacia de la división: aunque el resultado justo requiera la aplicación consistente y regular de una norma, de aquí no se sigue que la moralidad del resultado justo se transmita de alguna manera a la moralidad del acto de aplicación de la norma, acto que puede servir igualmente a la injusticia $y$, por lo tanto, ser un acto inmoral. $\mathrm{O}$, con otros términos ya utilizados, las condiciones necesarias de una acción no participan necesariamente de las cualidades de dicha acción. En definitiva, una cosa es aplicar normas y otra cosa es hacer justicia, y esto es así aunque se admita que el recurso a las normas puede ser el mejor instrumento para hacer justicia ${ }^{66}$.

La segunda razón en favor de la moralidad de la justicia formal parece más fuerte y nos remite, de nuevo, al ideal de la autonomía individual: la acción formalmente justa contribuye a aumentar la autonomía individual

(Filadelfia, Temple University Press, 1987), págs. 231-237, y por R. Escudero, Positivismo y moral interna del derecho, cit., pág. 423 y sigs.; puede verse también mi trabajo "Acerca de la moralidad intrínseca del derecho" (en Derechos y libertades, n 10, 2001, págs. 199-213).

${ }^{65}$ F. Schauer, Playing by the Rules (Oxford, Clarendon Press, 1991), pág. 137: "No hay nada esencialmente justo en la toma de decisiones basada en normas. No hay razón para creer, y mucha razón para no creer, que la toma de decisiones basada en normas es intrínsecamente más justa que la toma de decisiones en la que las normas no bloquean al que toma las decisiones..."

${ }^{66}$ Véase D. Lyons, Ética y derecho, cit., págs. 86-90 y “On Formal Justice”, cit., 28-32. 
respetando la expectativa creada previamente por una norma, incluso cuando esta norma es materialmente injusta ${ }^{67}$. Nos hallamos, pues, ante algo muy similar al argumento de la autonomía en su primera versión, según el cual, "la seguridad jurídica es condición suficiente de la autonomía". En el epígrafe $a$ de la sección 2 concluí que tal argumento no sirve para mostrar que la seguridad jurídica tiene valor moral, basándome en el hecho de que la autonomía que la seguridad jurídica es capaz de garantizar por sí sola (con completa independencia del contenido material de las normas) no es una autonomía moralmente valiosa. Ahora, frente a este modo de argumentar el valor moral de la justicia formal, cabe oponer algo equivalente: la autonomía que la justicia formal es capaz de garantizar por sí sola no es una autonomía moralmente valiosa. Esto es fácil de comprender si se tiene en cuenta la relación conceptual establecida más arriba entre la seguridad jurídica y la justicia formal: la justicia formal no es sino uno de los elementos necesarios (una condición necesaria) de la seguridad jurídica; por eso, la autonomía que puede garantizarse por medio de la aplicación formalmente justa de una norma no puede diferir de la autonomía que puede garantizarse por medio de la seguridad jurídica generada por dicha norma.

Conviene observar que la justicia formal puede garantizar una autonomía moralmente valiosa también cuando la norma aplicada es injusta, siempre que la conjunción del contenido de la norma con el hecho de su inaplicación lesione significativamente la autonomía de alguien. En este caso, el valor moral que percibimos es el de la justicia material, porque la lesión de la autonomía individual es una injusticia material. Además, como estamos en el supuesto de aplicación de una norma materialmente injusta, el aplicador puede encontrarse ante el dilema de decidir entre dos injusticias materiales, la que causará al aplicar correctamente la norma y la que causará al no aplicarla correctamente. Puede ser cierto, como ha señalado Rawls, que "incluso donde las leyes y las instituciones son injustas, es a menudo mejor que sean aplicadas consistentemente" ${ }^{98}$; pero esto no debe tomarse como una prueba del valor intrínseco de la justicia formal, sino como la constatación de que la injusticia material contenida en la lesión de la autonomía causada por la aplicación inconsistente de las normas injustas suele ser mayor que la injusticia material causada por su aplicación consistente.

Esto puede comprobarse con el análisis de un ejemplo propuesto por un defensor de la justicia formal. Tom Campbell ha escrito que "la aplicación

${ }^{67}$ Es bien conocida la insistencia de Bentham en la necesidad de respetar las "expectativas" (legítimas o no) como modo de fomentar el progreso social; sobre esto pueden verse sus "Principios del Código Civil" en J. Bentham, Tratados de legislación civil y penal (trad. R. Salas, ed. M. Rodríguez Gil, Madrid, Editora Nacional, 1981).

${ }^{68}$ J. Rawls, A Theory of Justice, cit., pág. 59. 
inconsecuente de reglas de adjudicación de cargas o beneficios no es un mero obrar técnicamente ineficiente o una inconsecuencia lógica, sino un verdadero tipo de injusticia que es bien distinto del tipo de carga o beneficio en cuestión, así como de las razones por las que en su momento se adoptaron dichas reglas". El ejemplo con el que apoya su defensa es el siguiente: "Así, en el caso de una regla arbitraria que estableciera que a las personas pelirrojas se les pague en el trabajo un día extra cada semana, se percibirá como formalmente injusto el hecho de que algunos pelirrojos no reciban el inmerecido y discriminatorio beneficio mientras que otras personas pelirrojas sí lo reciban" $"$. Un pelirrojo que no recibe el día extra de salario puede aducir que, al margen de que se considere injusto que los pelirrojos cobren un día extra, el hecho de que algunos pelirrojos lo cobren y él no es, en sí, injusto. Lo que habrá que contestarle es que lo que en realidad es injusto es que algunos pelirrojos cobren un día extra y no lo cobren los demás trabajadores, sean o no sean pelirrojos (asumiendo que el hecho de ser pelirrojo no es motivo que justifique mayor salario). Contra esta consideración, lo que puede añadir el pelirrojo es algo que tiene que ver con la previa existencia de la norma, por ejemplo, que él ha planificado ciertas actividades onerosas en función de la expectativa de mayor salario suscitada por la norma y que ahora sufrirá un perjuicio, económico o de otro tipo, derivado de la frustración de la expectativa. Esto bien puede ser cierto y, sin duda, la frustración de la expectativa es injusta, pero calificar esta injusticia como "formal" es inapropiado, porque se trata de una injusticia material: una pérdida económica, o el malestar derivado de no poder satisfacer un deseo; en definitiva, una restricción de su autonomía. Si tenemos en cuenta la razón que animó al aplicador de la norma a violarla en este caso, podemos precisar lo siguiente: si era una razón justa (favorecer a un trabajador más laborioso o a un trabajador más necesitado), el aplicador ha intentado causar la menor injusticia material posible, y ha considerado menor la que consiste en la frustración de la expectativa del pelirrojo; por lo tanto, la acción del aplicador de la norma, unitariamente considerada, no es injusta. Si era una razón injusta (favorecer a un trabajador que le cae simpático y que no reúne ni más ni menos méritos que el pelirrojo), la inaplicación de la norma produce una injusticia: la frustración de la expectativa del pelirrojo, y por la razón explicada; pero esta injusticia no tiene por qué ser mayor que la que sufriría el otro trabajador si la norma fuese respetada, esto es, si el día extra lo recibiese el pelirrojo, que no tiene más méritos que él. Siendo así, no se ve en qué sentido el pelirrojo podría decir que ha sufrido una injusticia "formal"; ha sufrido una injusticia pero, contra lo que sostiene Campbell, ésta no es de un tipo "bien distinto

\footnotetext{
${ }^{69}$ T. Campbell, La justicia, cit., pág. 41; véanse en general las págs. 39-45.
} 
del tipo de carga o beneficio" asignado por la norma. Lo podemos apreciar mejor cambiando el ejemplo: si la norma dijese "se pagará un día menos de salario a los pelirrojos", y si la violación de la norma consistiese en no restar a nuestro pelirrojo un día de salario, éste no podría quejarse de injusticia, aunque la supuesta "injusticia formal" se haya cometido igualmente; esto es así porque sólo las injusticias materiales suscitan quejas, y aquí no hay más injusticia material que la que se haya cometido con los demás pelirrojos, a los que antes se les pagó un día menos de salario; ¿podrían quejarse ellos? Un poco más adelante me ocuparé de un caso similar a éste, pero adelanto que la respuesta tendrá que tener en cuenta las razones que han llevado al encargado de los salarios a no aplicar la norma en este caso concreto.

En síntesis, puede afirmarse que: (1) la no aplicación regular y consistente de una norma jurídica supone la lesión de una expectativa; (2) la lesión de una expectativa es, en muchos casos, una conducta moralmente incorrecta; (3) la razón de esta incorrección es que en esos casos se menoscaba la autonomía del individuo cuya expectativa se lesiona, y este menoscabo es una injusticia material; (4) si la lesión de la expectativa no produce menoscabo de la autonomía, no hay injusticia ni, por tanto, incorrección moral; (5) por tanto, no hay nada intrínsecamente inmoral en la no aplicación regular y consistente de las normas jurídicas y siempre habrá que estar al contenido material de la norma aplicable para determinar si su violación produce injusticia o no. Por eso, "en general, todo lo que puede decirse es que la fuerza de las exigencias de la justicia formal, de la obediencia al sistema, claramente depende de la justicia sustantiva de las instituciones y de las posibilidades de su reforma" ${ }^{70}$.

Como complemento del análisis precedente, voy a examinar un intento de rehabilitación del valor moral de la igualdad ante la ley, entendida como equivalente de la justicia formal; está contenido en un trabajo de Alfonso Ruiz Miguel y se dirige fundamentalmente contra la ya citada tesis kelseniana de la irrelevancia moral de la igualdad ante la ley, o justicia formal ${ }^{71}$. Su propósito es poner en cuestión el siguiente modo de razonar: "cuando la norma es injusta, el principio de igualdad ante la ley es insuficiente porque no sirve para detener la injusticia, y cuando la norma es justa, el principio es innecesario porque bastaría con aplicar la norma correctamente (no igualmente): en ambos casos, la igualdad ante la ley sería éticamente irrelevante"; sin embargo, Ruiz Miguel entiende que "ésta es una alternativa demasiado cruda, presumiblemente basada en casos definidos, que no capta la complejidad de la aplicación de normas en el seno de los sistemas

\footnotetext{
${ }^{70}$ J. Rawls, A Theory of Justice, cit., pág. 59 (la cursiva es mía).

${ }^{71}$ A. Ruiz Miguel, "Equality Before the Law and Precedent", citado.
} 
jurídicos". Por tanto, el valor del principio de igualdad ante la ley debe ser apreciado en casos intermedios, y en el trabajo se proponen varios de estos casos, en los que se intuye algún defecto moral sólo identificable atribuyendo valor moral a la igualdad ante la ley. Comentaré sólo tres de ellos, con la confianza de que sean suficientemente significativos de lo que Ruiz Miguel quiere hacernos ver.

El primer ejemplo consiste en comparar la aplicación de dos normas injustas pertenecientes a un sistema jurídico genéricamente injusto, siendo una de ellas mucho más injusta que la otra. La primera es la norma que exige aplicar la pena capital a judíos políticamente desobedientes, en tanto que la segunda es una norma que prohibe el nudismo en las playas; ambas son normas eficaces en el sentido de que son aplicadas regularmente. Llegado el caso de aplicar una vez más la primera norma, Ruiz Miguel considera "absurdo" pensar que un juez estaría vinculado moralmente por el principio de igualdad ante la ley si tiene la posibilidad de evitar tal aplicación y, así, salvar la vida de un judío políticamente desobediente. En cambio, si la norma que prohibe el nudismo en las playas ha sido violada por un el hijo de un hombre rico y poderoso, un juez puede razonablemente tener en cuenta el principio de igualdad ante la ley y aplicarle el castigo previsto por la norma. Esta comparación, explica, "significa que incluso en sistemas jurídicos injustos el principio de igualdad ante la ley sigue teniendo algún peso"72, aunque muy bajo en comparación con la injusticia material de la norma y de su aplicación. El segundo ejemplo es el de una norma ligeramente injusta, caso en el cual el peso de la igualdad ante la ley se observa con mayor claridad. Una oficina pública, de acuerdo con la norma vigente, expide sus certificados al día siguiente de haber sido solicitados; un individuo que parece ser amigo de los oficinistas solicita el certificado y éste le es expedido en cinco minutos; yo, que veo a los oficinistas ociosos, creo justo que a mí también se me expida el certificado en el momento, y todavía más justo que se le haga esperar al amigo hasta mañana (es decir, que se le trate como a todo el mundo), incluso aunque la norma que exige esperar un día nos parezca injusta y aunque los oficinistas estén ociosos en ese momento. Ruiz Miguel sostiene que, si no fuese por el peso moral de la igualdad ante la ley, no podríamos formular esta última opinión. El tercer ejemplo se sitúa en la misma oficina del ejemplo anterior, donde sigue rigiendo la misma norma; pero, en este caso, la norma no es aplicada habitualmente, sino que, cuando pido mi certificado, me informan de que lo expiden siempre en el acto. En ese momento, aparece otro individuo que presenta su solicitud de certificado; por alguna razón, comienza a discutir con el oficinista, que acaba diciéndole que vuelva

\footnotetext{
${ }^{72}$ A. Ruiz-Miguel, loc. cit., pág. 381.
} 
el día siguiente a recoger el certificado (se supone que para fastidiarlo). Ruiz Miguel se pregunta: “¿No es esta una conducta injusta y arbitraria debido a su desprecio del principio de igualdad ante la ley? ¿No puede decirse que tal desigualdad injusta es un resultado peor que continuar sin aplicar la norma ni, en este caso particular, el principio de legalidad?"73

Examinemos ahora los tres ejemplos de aplicación o inaplicación de normas, sus posibles defectos morales y el posible peso moral de la igualdad ante la ley que cabe inducir a partir de los mismos. En el primer ejemplo, el hecho de que el nudista sea el hijo de un hombre rico y poderoso es considerado como una circunstancia relevante; supongamos, hipotéticamente, que todos los nudistas condenados previamente eran hijos de hombres ni ricos ni poderosos. Sin embargo, no acaba de verse la razón moral que puede haber para condenar al hijo del hombre rico si la norma es considerada injusta. Ser hijo de rico, o rico, no debería estar relacionado con ser condenado por bañarse desnudo en la playa. Los previamente condenados no tienen razones morales para quejarse de que al hijo del rico no se le condene; sí tienen razones morales para quejarse de que ellos sean condenados (pero esta queja se basa en la injusticia material que supone castigar a los que se bañan desnudos) y también tienen razones morales para quejarse de que el hijo del rico sea absuelto porque es hijo de rico (esta queja se basa también en la justicia material: ser hijo de rico no es un dato relevante en este caso). Las aplicaciones anteriores de la norma son materialmente injustas; ésta también lo será; y también lo será su inaplicación si está en función de la riqueza del padre del nudista, pero no si está en función de la injusticia material que supone condenar a un hombre cualquiera por bañarse desnudo. Si la circunstancia de la riqueza del padre es relevante, pensemos qué sucedería si el nudista fuese el hijo de un mendigo: ¿dejaría de pesar el principio de igualdad ante la ley y habría que absolverlo por razones morales, considerando que la injusticia material pesa ahora más que la injusticia derivada del desigual trato? Precisamente, tener en cuenta si el padre del nudista es pobre o rico supone una conducta materialmente injusta, porque tal circunstancia en nada modifica la relevancia que pueda atribuirse a bañarse desnudo. Cierto es que el ejemplo podría interpretarse de manera que la circunstancia de la riqueza del padre del nudista fuese relevante: (1) suponiendo que la norma establezca una pena pecuniaria, menos gravosa para los hijos de ricos que para los hijos de pobres; (2) suponiendo que el hijo del hombre rico podía practicar el nudismo en la piscina privada de la familia, cosa que no pueden hacer los otros; (3) suponiendo que el juez (socialista convencido) cree que contribuye a la lucha por la igualdad social castigando injustamente al que, por otras

\footnotetext{
${ }^{73}$ A. Ruiz-Miguel, loc. cit., pág. 382.
} 
razones (la riqueza familiar), ostenta una posición social injusta. En los tres casos, el juez actúa por razones de justicia material y no de igualdad ante la ley. En definitiva, el juez que castiga al nudista hijo de rico porque es hijo de rico o bien actúa incorrectamente o bien, si actúa correctamente, lo hace por razones de justicia material.

En el segundo ejemplo, la expedición del certificado en el mismo día para el amigo del oficinista constituye un acto ilegal, aunque puede que justo desde un punto de vista material. La discordancia entre legalidad y justicia deriva de la injusticia de la norma, que habría tenido que expresarse en otros términos ("no deberá esperarse hasta el día siguiente si los oficinistas tienen tiempo de expedir el certificado en el mismo día", o algo así). En este caso, hay que distinguir el hecho de expedir un certificado en el mismo día y el hecho de expedir un certificado en el mismo día a un amigo. El oficinista se comporta ilegalmente no porque expida un certificado en el mismo día $a$ su amigo, sino porque expide un certificado en el mismo día. En cuanto a la justicia del acto, es justo que el certificado sea expedido en el mismo día si el oficinista tiene tiempo para ello, con independencia de que el solicitante sea su amigo o no lo sea. Ahora bien, si el motivo del trato dispensado no es el hecho específico de tener tiempo libre, sino el hecho de que el solicitante sea amigo del oficinista, nos hallamos ante un acto materialmente injusto (pero no por razón del trato dispensado, sino por razón del motivo del trato dispensado). Esta injusticia material se pone de manifiesto cuando una segunda persona acude a solicitar el certificado y el oficinista, aunque tiene tiempo libre, se niega porque esta segunda persona no es amiga suya. Con esta segunda persona se está cometiendo una injusticia material, puesto que ser amigo del oficinista no constituye una justificación para recibir mejor trato en la expedición de certificados (con independencia de que tal mejor trato sea recibido mediante la violación de una norma). Podemos preguntarnos: ¿qué sucedería si el solicitante afortunado no fuese amigo del oficinista? ¿Dejaría de pesar moralmente el principio de igualdad ante la ley? Si todos los solicitantes que encontraron ocioso al oficinista recibieron su certificado en el mismo día, no hay injusticia alguna; si sólo lo recibieron los amigos del oficinista y a los demás se les hizo esperar un día, se trata de una injusticia material porque, insisto, ser amigo del oficinista no es relevante para obtener el certificado un día antes o un día después, ni tampoco para recibirlo de acuerdo con la ley o al margen de la ley. Por tanto, la legítima queja del que no es amigo del oficinista se funda en última instancia en la justicia material y no en la igualdad ante la ley.

Por último, el tercer ejemplo puede ser analizado en los términos del anterior: en el caso presente, el oficinista que, por antipatía, rechaza expedir el certificado en el mismo día, opta por ceñirse a la norma (actúa legalmente) 
pero en contra del principio de igualdad ante la ley: ¿es esto inmoral? En primer lugar, cabe dudar de que esta actuación vaya contra el principio de igualdad ante la ley, puesto que la norma es sistemáticamente incumplida, pero cumplida en este caso concreto. La actuación estaría, más bien, en contra del principio de igualdad de trato, o justicia material, salvo que el hecho de que todos sean tratados igualmente al margen de la ley se considere un caso de aplicación del principio de igualdad ante la ley; no obstante, esto es secundario ahora. Si todos los solicitantes anteriores recibimos el certificado en el mismo día, también el solicitante actual deberá recibirlo, pues se halla en las mismas condiciones materialmente relevantes; que haya discutido con el oficinista o que éste quiera fastidiarlo no son circunstancias relevantes, y si se le expide el certificado con un día de demora se cometerá con él una injusticia material; de aquí deriva la inmoralidad de la conducta del oficinista, no del principio de igualdad ante la ley.

\section{e) Conclusión}

Si se aceptan los razonamientos del epígrafe anterior, la moralidad de la justicia formal o de la igualdad ante la ley ha quedado sin acreditar, puesto que no la prueba ninguna de las dos razones propuestas: ni la vinculación de la justicia formal con la justicia material ni el respeto de la autonomía individual producido por la justicia formal. Por tanto, tampoco puede aceptarse el argumento de la justicia formal en favor de la tesis del valor moral de la seguridad jurídica, puesto que depende de la aceptación de la moralidad de la justicia formal. Así lo entiendo, aunque soy consciente de que el concepto de justicia formal y, en particular, su conexión con la autonomía individual, exigen un examen más cuidadoso del que he desarrollado aquí ${ }^{74}$.

\section{Cuestiones pendientes}

El propósito de este trabajo era cuestionar los argumentos más fuertes ofrecidos en favor de la tesis del valor moral de la seguridad jurídica; es lo que he intentado hacer en las tres secciones anteriores. Sin embargo, la cautela que acabo de imponer al análisis del argumento de la justicia formal puede extenderse también a los otros dos: cada uno de ellos requiere mayor atención. Por lo tanto, una primera cuestión pendiente es la de refinar el análisis de este tipo de argumentos, lo cual exige también clarificar las relaciones conceptuales entre la seguridad jurídica y otras nociones que he considerado afines a ella.

\footnotetext{
${ }^{74}$ En todo caso, ténganse en cuenta los ya citados análisis críticos de D. Lyons, "On Formal Justice”, y M. Kramer, "Justice as Constancy”, en los que pueden encontrarse más, y más elaboradas, razones en contra del valor moral de la justicia formal.
} 
Si mi análisis de los argumentos fuese acertado, ninguno de ellos serviría para sostener la tesis del valor moral de la seguridad jurídica; ahora bien, como es obvio, ello no probaría que la tesis sea incorrecta, sino sólo que tales argumentos no son suficientes para probar su corrección y, acaso, que no es plausible defenderla en tanto no se aporten argumentos nuevos. Una forma de probar que la tesis es incorrecta consistiría en mostrar que la seguridad jurídica tiene una naturaleza estrictamente técnica o instrumental, desplazándola así desde el ámbito de los principios ético-políticos hasta el ámbito de los mecanismos institucionales ${ }^{75}$. Creo posible ensayar una caracterización tal haciendo ver que la seguridad jurídica no es sino la eficacia de un sistema jurídico en tanto sistema normativo, a través de una reflexión acerca del vínculo existente entre las nociones de derecho, eficacia del derecho y seguridad jurídica ${ }^{76}$. Es una segunda cuestión pendiente.

Si se aceptase que la seguridad jurídica tiene un significado estrictamente instrumental, en tanto mera eficacia normativa de un sistema jurídico, sería interesante plantear una tercera cuestión, a saber, la de por qué la seguridad jurídica ha sido considerada como un valor moral. Una manera adecuada de abordar esta cuestión es adoptar un punto de vista histórico e indagar la configuración de la idea de seguridad jurídica a lo largo del tiempo y las condiciones en que se le ha atribuido valor moral. En particular, habría que prestar atención al modo en que la seguridad jurídica se constituyó en valor supremo para la cultura jurídica liberal burguesa de los siglos XIX y XX. Aunque mucho se ha escrito al respecto, merece la pena volver sobre ello.

Hay que advertir, en fin, de que el hecho de negar el carácter moral a la seguridad jurídica no significa que no pueda haber un deber moral de promoverla. Este deber moral puede estar justificado previo un análisis de los fines y medios específicos que constituyen cada sistema jurídico particular. Cuando el juicio de moralidad de sus fines y de sus medios específicos sea positivo, será posible afirmar que la seguridad jurídica, en tanto medida de la perfección o excelencia de un sistema jurídico, genera deberes morales para todos aquéllos (legisladores, jueces, abogados, profesores, etc.) que desempeñan funciones jurídicas, y respecto de estas funciones, en tanto que ellas sean consideradas como medios apropiados moralmente para alcanzar

\footnotetext{
${ }^{75}$ Véase esta distinción en F. Laporta, "El ámbito de la constitución” (en Doxa, n 24, 2001, págs. 459-484), pág. 473.

${ }^{76}$ Echo de menos esta perspectiva en el, por lo demás, excelente trabajo de L. L. Hierro, $L a$ eficacia de las normas jurídicas (Barcelona, Ariel, 2003). Sugiero, entre otros trabajos importantes, el libro de M. Corsale, Certezza del diritto e crisi di legittimità (Milán, Giuffrè, $2^{\mathrm{a}}$ ed., 1979), además de los ya citados L. L. Fuller, The Morality of Law y J. Raz, "The Rule of Law and its Virtue", al margen ahora de las consideraciones axiológicas que contienen.
} 
fines apropiados moralmente. De este modo, cabría intentar la elaboración de una ética común a todas las profesiones jurídicas en la que la noción de seguridad jurídica sería la pieza central ${ }^{77}$.

${ }^{77}$ En relación con ello véase T. Campbell, "El sentido del positivismo jurídico" (en Doxa, $\mathrm{n}^{\mathrm{o}} 25,2002$, págs. 303-331). 